\title{
Evaluation of a global aerosol microphysics model against size-resolved particle statistics in the marine atmosphere
}

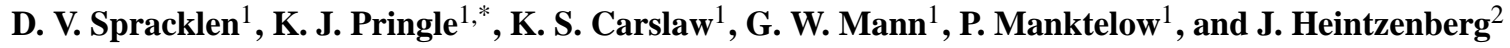 \\ ${ }^{1}$ Institute for Atmospheric Science, School of Earth and Environment, University of Leeds, UK \\ ${ }^{2}$ Leibniz-Institute for Tropospheric Research, Permoserstr., 04318 Leipzig, Germany \\ *now at: Met Office, Hadley Centre, Exeter, UK
}

Received: 4 September 2006 - Published in Atmos. Chem. Phys. Discuss.: 21 September 2006

Revised: 29 March 2007 - Accepted: 1 April 2007 - Published: 26 April 2007

\begin{abstract}
A statistical synthesis of marine aerosol measurements from experiments in four different oceans is used to evaluate a global aerosol microphysics model (GLOMAP). We compare the model against observed size resolved particle concentrations, probability distributions, and the temporal persistence of different size particles. We attempt to explain the observed sub-micrometre size distributions in terms of sulfate and sea spray and quantify the possible contributions of anthropogenic sulfate and carbonaceous material to the number and mass distribution. The model predicts a bimodal size distribution that agrees well with observations as a grand average over all regions, but there are large regional differences. Notably, observed Aitken mode number concentrations are more than a factor 10 higher than in the model for the N Atlantic but a factor 7 lower than the model in the NW Pacific. We also find that modelled Aitken mode and accumulation mode geometric mean diameters are generally smaller in the model by $10-30 \%$. Comparison with observed free tropospheric Aitken mode distributions suggests that the model underpredicts growth of these particles during descent to the marine boundary layer (MBL). Recent observations of a substantial organic component of free tropospheric aerosol could explain this discrepancy. We find that anthropogenic continental material makes a substantial contribution to N Atlantic MBL aerosol, with typically 60-90\% of sulfate across the particle size range coming from anthropogenic sources, even if we analyse air that has spent an average of $>120 \mathrm{~h}$ away from land. However, anthropogenic primary black carbon and organic carbon particles (at the emission size and quantity assumed here) do not explain the large discrepancies in Aitken mode number. Several explanations for the discrepancy are suggested. The lack of lower atmospheric particle formation in the model may explain low $\mathrm{N}$ Atlantic particle concentrations. However, the observed and
\end{abstract}

Correspondence to: D. V. Spracklen

(dominick@env.leeds.ac.uk) modelled particle persistence at Cape Grim in the Southern Ocean, does not reveal a diurnal cycle consistent with a photochemically driven local particle source. We also show that a physically based cloud drop activation scheme better explains the observed change in accumulation mode geometric mean diameter with particle number.

\section{Introduction}

Marine aerosol plays an important role in global climate. Oceans cover a large fraction of the Earth's surface and cloud condensation nuclei $(\mathrm{CCN})$ concentrations in the marine boundary layer (MBL) are typically lower than over continental regions, making marine stratocumulus clouds particularly susceptible to change from anthropogenic sources (Pawlowska and Brenguier, 2000).

Sea spray plays an obvious and well documented role in maintaining super-micrometre particle concentrations in the MBL (Fitzgerald, 1991), but its contribution to submicrometre particle concentrations is less well understood. Recently, techniques have become available that allow the chemical characterisation of sub-micrometre aerosol and subsequent observations have shown sea salt aerosol with dry diameters down to as small as $10 \mathrm{~nm}$ (Bigg et al., 1995; O'Dowd et al., 1997; Nilsson et al., 2001; Zhou et al., 2001; Geever et al., 2005; Clarke et al., 2006). Recent sea salt aerosol source functions now calculate sea salt production down to these smaller sizes (Gong, 2003; Martensson et al., 2003; Clarke et al., 2006). In addition, particulate organic matter is now known to contribute to sub-micrometre aerosol mass (Leck and Bigg, 2005a; O'Dowd et al., 2004). There is also new evidence suggesting that during the summer in the Arctic, primary particulate matter from marine biogenic sources may be an additional source of marine aerosol (Bigg et al., 2004; Heintzenberg et al., 2006; Leck and Bigg, 1999; Leck et al., 2002, 2004; Leck and Bigg, 2005a,b; Lohmann

Published by Copernicus GmbH on behalf of the European Geosciences Union. 
and Leck, 2005). The relative contribution of this source and its geographical extent outside the Arctic is so far unknown.

A number of modelling studies have advanced our understanding of what physical processes determine the particle size distribution in the MBL (e.g., Kreidenweis et al., 1991; Raes and Van Dingenen, 1992; Lin et al., 1992; Pandis et al., 1994; Russell et al., 1994; Raes, 1995; Capaldo et al., 1999; Katoshevski et al., 1999; Pirjola et al., 2000). Observations and models show that entrainment of aerosol from the free troposphere (FT) is important in maintaining MBL aerosol concentrations (Raes, 1995; Covert et al., 1996; Raes et al., 1997; Bates et al., 1998b). Aerosol in the FT immediately above the MBL is reasonably constant in time because particles formed in the cold upper troposphere have time to evolve into a self-preserving size distribution through slow subsidence of air. This persistence of the overlying aerosol is believed to sustain a fairly constant MBL aerosol despite periodic scavenging of the larger sea salt particles.

The extent to which the aerosol distribution is repopulated by local nucleation processes is not clear. A statistical analysis of observed remote MBL aerosol distributions shows that particles below $10 \mathrm{~nm}$ diameter only occur in 3\% of the observations (Heintzenberg et al., 2004), although regions such as the $\mathrm{N}$ Atlantic do have a statistically significant ultrafine mode around $20 \mathrm{~nm}$ dry diameter. These observations suggest that in situ particle production in the MBL is limited, although there is evidence that nucleation may be important in coastal areas (O'Dowd et al., 1999) and ultrafine particles may be formed after precipitation scavenging of existing aerosol (Clarke et al., 1998; Covert et al., 1992, 1996; Weber et al., 1995, 1998).

Much of our understanding of MBL aerosol has stemmed from the results of box and single column model simulations (e.g., Kreidenweis et al., 1991; Raes and Van Dingenen, 1992; Lin et al., 1992; Pandis et al., 1994; Russell et al., 1994; Raes, 1995; Capaldo et al., 1999; Katoshevski et al., 1999; Pirjola et al., 2000). These simulations have examined the maintenance of MBL Aitken and accumulation mode aerosol through a combination of sea spray emission and entrainment from the FT. The idealised nature of most of these studies and the limited spatial scale of the models means that they have not been able to assess the importance of continental aerosol sources. Several sophisticated global aerosol models have been developed, a need originally highlighted by Raes et al. (1995) in order to fully understand MBL aerosol. These models allow changes in the aerosol size distribution to be predicted through calculation of the driving microphysical processes (Adams and Seinfeld, 2002; Ghan et al., 2001; Gong et al., 2002, 2003; Herzog et al., 2004; Lauer et al., 2005; Lauer and Hendricks, 2006; Rodriguez and Dabdub, 2004; Spracklen et al., 2005a,b; Stier et al., 2005; Verma et al., 2007; Vignati et al., 2004; Wilson et al., 2001). The principal advantage of a global model over a box or column model is that it naturally takes account of the spatial and temporal changes in aerosol in the MBL and overlying FT driven by variations in meteorology. In the box models, assumptions had to be made about the nature of the particles entrained from the FT into the MBL. Global model FT aerosol varies depending on regional variations in source gas concentrations (di-methyl sulfide (DMS), sulfur dioxide $\left(\mathrm{SO}_{2}\right)$ ), vertical transport in clouds and subsidence rates. Global models also account for the long-range transport of aerosol, including that derived from continental primary emissions, marine DMS and anthropogenic $\mathrm{SO}_{2}$, while box model studies have been limited to single columns of the atmosphere influenced by local emissions only.

The availability of global aerosol microphysics models now permits a more detailed evaluation of our understanding of MBL aerosol. In Spracklen et al. (2005a) we showed that a global aerosol microphysics model of the sulfate and sea salt system (GLOMAP) is capable of capturing observed $\mathrm{CN}$ concentrations in the MBL and FT. We also showed that modelled particle size distributions are broadly in agreement with typical observations. GLOMAP simulates a surface mean MBL CN concentration of $465 \mathrm{~cm}^{-3}$ (Spracklen et al., 2005a) which compares well with the aerosol climatology of Heintzenberg et al. (2000) which gives a global average value (weighted by latitudinally binned ocean surface area) of about $490 \mathrm{~cm}^{-3}$. Adams and Seinfeld (2002) use a sectional scheme in the GISS general circulation model. For a sulfate-only simulation they report global mean surface (including the continental BL) CN number of $221 \mathrm{~cm}^{-3}$. Their more recent study (Pierce and Adams, 2006) suggests that sub-micrometre sea spray may enhance particle concentrations over the Southern Ocean by $150-500 \%$. However, the estimated contribution of sea spray emissions to CCN based on model simulations will depend very much on the modelled concentrations of sub-micrometre sulfate concentrations.

In this paper we use statistical analyses of observed remote MBL aerosol (Heintzenberg et al., 2000, 2004) to carry out a comprehensive evaluation of the factors controlling its properties. We extend previous comparisons of modelled and observed integral variables like $\mathrm{CN}$ and $\mathrm{CCN}$ to a full evaluation of the size distribution. This comparison will be the basis from which we can build an understanding of how biogenic and anthropogenic continental sources impact the marine aerosol distribution.

\section{Model description}

GLOMAP is an extension to the TOMCAT global 3D off-line Chemical Transport Model (e.g., Chipperfield et al., 1993; Chipperfield, 2006; Stockwell and Chipperfield, 1999). A detailed description of GLOMAP is given in Spracklen et al. (2005a). The aerosol distribution is described using a sectional scheme with 20 bins spanning dry diameters from about $3 \mathrm{~nm}$ to $25 \mu \mathrm{m}$. Two moments are simulated in each size section (particle number density and mass 
per particle). Carrying two moments for each size section allows the average particle mass in each bin to vary, whereas this is fixed in single moment schemes.

In the baseline runs presented here, GLOMAP is restricted to sea salt and sulfate aerosol. We then explore the impact of including primary emissions of black carbon (BC) and organic carbon (OC) on the remote MBL aerosol distribution. To minimise computational expense we simulate all aerosol components in one internally mixed distribution. That is we assume instantaneous mixing of all aerosol components in any size bin. We assume this internally mixed distribution to have the physical and chemical properties of sulfate aerosol. The most important effect of this simplification is to artificially increase the particle scavenging efficiency of BC and OC particles in clouds (through drop formation on the more hygroscopic acidic particles). We estimate the importance of this on model $\mathrm{CN}$ number. Complete removal of in-cloud scavenging in the model increased CN globally by only $10 \%$.

The rate of emission of sea salt aerosols from the ocean is uncertain (Lewis and Schwartz, 2004). Here we use the emission parameterisation of Gong (2003) which calculates sea salt flux between $70 \mathrm{~nm}$ and $20 \mu \mathrm{m}$ dry diameter. The Gong (2003) scheme extends the range of the Monahan et al. (1986) scheme to particle sizes below $0.2 \mu \mathrm{m}$ where the original scheme had been found to overestimate sea salt flux. A recent global model study by Pierce and Adams (2006) has used new sea salt schemes (Clarke et al., 2006; Martensson et al., 2003), which emit sea salt aerosol down to sizes as small as $10 \mathrm{~nm}$ dry diameter. This study found that over the Southern Ocean this ultrafine sea salt can increase CCN concentrations by more than $50 \%$.

Oceanic DMS emissions are calculated using sea surface DMS concentrations from Kettle et al. (1999) and the seato-air transfer velocity of Liss and Merlivat (1986). Volcanic $\mathrm{SO}_{2}$ emissions are from Andres and Kasgnoc (1998). Anthropogenic $\mathrm{SO}_{2}$ emissions are from Benkovitz et al. (1996). In the baseline model all anthropogenic sulfur is assumed to be emitted as gaseous $\mathrm{SO}_{2}$.

$\mathrm{BC}$ and $\mathrm{OC}$ aerosol from fossil fuel and biofuel combustion are emitted with a number mode radius of $15 \mathrm{~nm}$ and geometric standard deviation 1.8 and from biofuel sources with radius $40 \mathrm{~nm}$ according to Bond et al. (2004). BC and OC from wild fires are emitted according to Van der Werf et al. (2003) with number mode radius of $40 \mathrm{~nm}$ and geometric standard deviation of 1.8. There is some uncertainty as to the most appropriate size choice for primary emissions. As biomass burning aerosol plumes age the mode radius increases and the distribution width narrows (Dentener et al., 2006). Here we have chosen to emit particles at their freshly emitted size according to Dentener et al. (2006). Emissions from biofuel and fossil fuel are added to the lowest model layer. Emissions from wild fires are emitted between the surface and $6 \mathrm{~km}$ altitude (Dentener et al., 2006).

GLOMAP includes the processes of aerosol nucleation, condensation, growth, coagulation, wet and dry deposition, transport, and cloud processing as described in Spracklen et al. (2005a).

The mechanisms by which particle formation occurs in the atmosphere are highly uncertain. Suggested mechanisms include binary $\left(\mathrm{H}_{2} \mathrm{SO}_{4}-\mathrm{H}_{2} \mathrm{O}\right)$, ternary $\left(\mathrm{H}_{2} \mathrm{SO}_{4}-\mathrm{H}_{2} \mathrm{O}-\mathrm{NH}_{3}\right)$, ion-induced and kinetic activation schemes. Here we assume that binary nucleation is the only particle formation mechanism. Other nucleation schemes also take place in the atmosphere leading to observed BL particle formation events over many continental areas (Kulmala et al., 2004). The impact of these events on BL total particle number is studied in Spracklen et al. (2006). Binary homogeneous nucleation rates are uncertain to within several orders of magnitude. The most recent binary parameterisation (Vehkamäki et al., 2002), whilst more physically realistic, do not agree better with laboratory measurements than earlier schemes (Kulmala et al., 1998). Here we use the nucleation scheme of Kulmala et al. (1998) which calculates nucleation rates as a function of temperature, relative humidity and gas phase concentration of sulfuric acid. This scheme is valid down to temperatures of $233 \mathrm{~K}$. Below this temperature we use the rate at $233 \mathrm{~K}$ as described in Spracklen et al. (2005b).

The baseline model uses a simple scheme to activate aerosol to cloud droplets. All particles greater than $50 \mathrm{~nm}$ dry diameter are assumed activated in low stratiform clouds. The use of a globally constant activation diameter is restrictive as the size at which a particle can activate is sensitive to a range of quantities, including the in-cloud updraft velocity, the number of $\mathrm{CCN}$ present, and the particle composition. The aerosol activation parameterisation of Nenes and Seinfeld (2003) (hereafter referred to as NS03) has been implemented in GLOMAP to provide a physically more realistic calculation of aerosol activation. NSO3 is a physically based aerosol activation scheme which has minimal reliance on empirical data. NS03 has been shown to predict average cloud droplet number concentrations to within $\approx 20 \%$ of observed values in stratiform and cumuliform clouds (Meskhidze et al., 2005). Monthly mean cloud fraction is from the International Satellite Cloud Climatology Project D1 database (Rossow and Schiffer, 1999). GLOMAP includes both in-cloud and below-cloud aerosol wet deposition in convective and frontal precipitation as diagnosed by European Centre for MediumRange Weather Forecasts (ECMWF) analyses.

Model runs presented here use a spatial resolution of $2.8^{\circ} \times 2.8^{\circ}$ latitude $\times$ longitude with 31 hybrid $\sigma$-p levels extending from the surface to $10 \mathrm{hPa}$. Large-scale atmospheric transport is specified from European Centre for MediumRange Weather Forecasts (ECMWF) analyses at 6-hourly intervals. Tracer advection is performed using the scheme of Prather (1986). Sub-grid transport is calculated using the convection scheme of Tiedtke (1989) and turbulent mixing in the boundary layer is calculated using the parameterisation of Holtslag and Boville (1993). 
Table 1. Marine aerosol observations used by Heintzenberg et al. (2004) to compile an average MBL aerosol distribution. For each experiment the number of observation points and the percentage of observations with back trajectories of greater than $120 \mathrm{~h}$ travel time since continental contact are noted. Table adapted from Heintzenberg et al. (2004).

\begin{tabular}{|c|c|c|c|c|c|}
\hline Experiment & Location & Campaign period & $\begin{array}{c}\text { No. of } \\
\text { observations }\end{array}$ & $\begin{array}{c}\% \text { observations } \\
>120 \mathrm{~h}\end{array}$ & Reference \\
\hline ACE-1 & $\begin{array}{c}\text { Cape Grim, Southern Ocean } \\
40.8^{\circ} \mathrm{S}, 144^{\circ} \mathrm{E}\end{array}$ & Nov-Dec 1995 & 1686 & 81 & Covert et al. (1998) \\
\hline ACE-2 & $\begin{array}{c}\text { Sagres, NE Atlantic } \\
37^{\circ} \mathrm{N}, 9^{\circ} \mathrm{W}\end{array}$ & June-July 1997 & 2474 & 23 & Russell and Heintzenberg (2000) \\
\hline Aerosols99/ & Atlantic/ & Jan-March 1999 & 1966 & 80 & Bates et al. (2002) \\
\hline
\end{tabular}

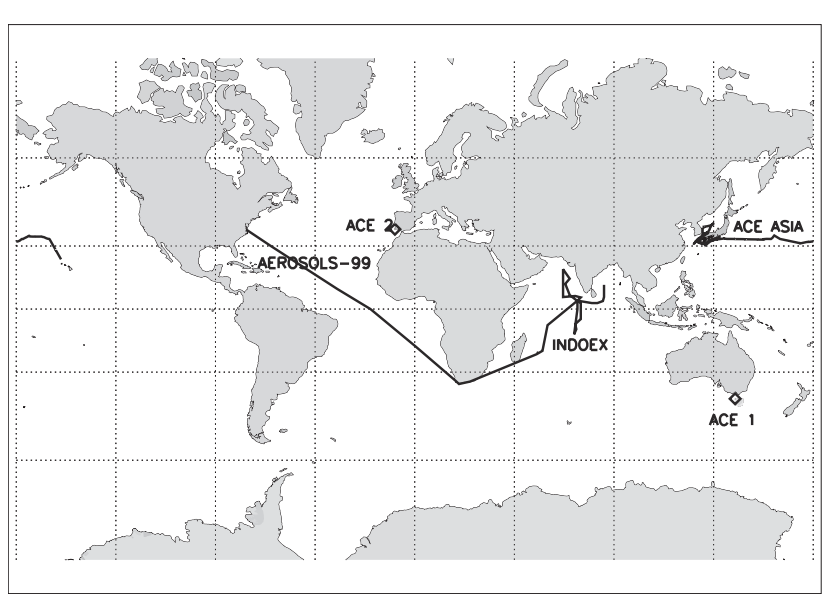

Fig. 1. Observations of marine aerosol used for comparison with model results. Ship cruises are indicated by lines and include Aerosols99 across the Atlantic in January 1999 (Bates et al., 2001), INDOEX in the Indian Ocean during March 1999 (Ramanathan et al., 2001) and ACE-Asia in the North Pacific during March and April 2001 (Huebert et al., 2003). The locations of two coastal stations are indicated (by open diamonds), one at Cape Grim, Tasmania used in ACE-1 (Bates et al., 1998a) and one at Sagres, Portugal used during ACE-2 (Raes et al., 2000).

\section{Observations}

We use MBL aerosol observations from two recently compiled statistical analyses (Heintzenberg et al., 2000, 2004). Heintzenberg et al. (2000) reviewed MBL observations made over the last 30 years and presented them on a $15^{\circ}$ latitude $\times 15^{\circ}$ longitude grid. Observations were made from January through December and cover $25 \%$ of the $15^{\circ}$ by $15^{\circ}$ ocean grid squares (see Fig. 1a of Heintzenberg et al. (2000)). The data were then further binned into $15^{\circ}$ latitude bands. Two latitude bands contained no observations $\left(75^{\circ} \mathrm{S}-90^{\circ} \mathrm{S}\right.$ and $60^{\circ} \mathrm{N}-90^{\circ} \mathrm{N}$ ). Distributions were fitted with 4 lognormal modes, but due to lack of data, global distributions were available only for the Aitken and accumulation modes.
Heintzenberg et al. (2004) compiled MBL observations from five marine aerosol experiments (ACE-1, ACE-2, ACEAsia, INDOEX and Aerosols99), which are summarised in Table 1. The location of the field campaigns is illustrated in Fig. 1. These experiments span virtually an annual cycle (January to April, June to July and November to December) and cover 4 different regions of ocean (Atlantic, Pacific, Indian and Southern Oceans) in both Northern and Southern Hemispheres. To minimise continental contamination, and to give a better description of remote 'background' MBL aerosol, Heintzenberg et al. (2004) filtered the observations to include data only with back trajectories of at least 120 hours without land contact. Heintzenberg et al. (2000) does not include any filtering to remove air masses with continental origin.

Aerosol size distributions were measured with a twin differential mobility particle spectrometer (TDMPS) with a minimum detection limit of $3 \mathrm{~nm}$ dry diameter. The upper size detection limit varied between 614 and $900 \mathrm{~nm}$ dry diameter. Counting statistics control the accuracy of particle counters at both the lower and upper particle size limit. Below $20 \mathrm{~nm}$ diameter, the low flow of sample air to the instrument results in high counting uncertainties (Heintzenberg et al., 2004). At the upper size limit of the instruments, low atmospheric concentrations also results in higher counting uncertainties. Heintzenberg et al. (2004) only included data where counting uncertainties were less than $100 \%$.

\section{Approach}

\subsection{Description of the model runs}

A series of simulations has been carried out starting with a baseline sulfate/sea-spray run and progressively incorporating further aerosol components or a refined treatment of specific processes.

1. Baseline sulfate/sea-spray run. We use the version of GLOMAP as described in Spracklen et al. (2005a). The model includes no primary particulate emissions from anthropogenic sources (all anthropogenic sulfur is emitted as a gas) and there are no emissions 
of carbonaceous particles. Activation of aerosol particles into cloud droplets occurs at a fixed particle size.

2. Additional species. Several model simulations are used to investigate the contribution of primary anthropogenic aerosol sources to the size distribution. First we assume a contribution from primary sulfate and then we include carbonaceous aerosol (from industrial and biomass burning sources).

3. Sensitivity to cloud processing. In these simulations we include a mechanistic calculation of cloud drop number in low-level clouds. The importance of these simulations is that they capture the dependence of activation diameter on the particle size distribution and should give more realistic conversion from Aitken to accumulation mode particles.

\subsection{Method of comparing model and observations}

The model was initialised with an aerosol-free atmosphere on 1 October, 1995, and spun up for 90 days. Results presented here are for an annual run for January-December 1996.

GLOMAP output was collocated with observations in both time and space by using surface model grid squares that lie within the geographic boundaries of the field experiment and during the calendar months when the different experiments took place. For Heintzenberg et al. (2000) the geographic boundaries are defined as the $15^{\circ}$ latitude by $15^{\circ}$ longitude squares where observations occurred. For Heintzenberg et al. (2004) the observations are from a combination of surface stations and ship-based measurements. The observations for ACE-1 and ACE-2 are from 2 surface stations at Cape Grim, Tasmania and Sagres, Portugal. For comparison with these stations we use ocean model grid squares immediately adjacent to the surface station. The observations for INDOEX/Aerosols99 and ACE-Asia are from ship-based measurements. Here we use model grid squares along the line of ship cruise.

Table 1 shows the number of observations in each field campaign that contribute to the distributions of Heintzenberg et al. (2004). Heintzenberg et al. (2004) combined results from all experiments to produce a "grand average" distribution. The modelled "grand average" size distribution is generated by weighting the results from model grid squares depending on the number of observational data points contributed from each campaign.

Heintzenberg et al. (2004) filtered out observations for which computed back trajectories passed over land within $120 \mathrm{~h}$ of the observation. To do likewise in GLOMAP we emit a tracer of known lifetime from all land masses and use the concentration of this tracer to calculate average age of air in any grid box. For comparison with Heintzenberg et al. (2004) we only include grid boxes where the average age of air exceeds $120 \mathrm{~h}$. Throughout the paper the size of particles reported is the particle dry diameter.

\section{MBL number-size distribution}

\subsection{General properties of the global MBL aerosol}

Here we compare the baseline GLOMAP model of sulfate and sea spray with MBL observations from all the marine experiments (termed the "grand average" by Heintzenberg et al., 2004). Figure 2a compares the GLOMAP sizedependent 5th, 50th and 95th percentiles of number concentrations and the observations from Heintzenberg et al. (2004). This comparison is shown also as a probability density function (PDF) of the number concentrations $\left(N\left(d_{p}\right)=d N\left(d_{p}\right) / d \log \left(d_{p}\right)\right)$ with respect to the particle dry diameter $\left(\mathrm{d}_{p}\right)$ in Fig. 2 b. We note that at small particle diameters, observations end at between 6 and $20 \mathrm{~nm}$ depending on the particle number concentration, whereas the model ends at smaller particle sizes. This is caused by counting statistics in the particle sensors resulting in large uncertainty at small diameters (Heintzenberg et al., 2004) and does not imply any discrepancy with the model.

The baseline model run predicts a median particle number (particles greater than $3 \mathrm{~nm}$ diameter) concentration of $250 \mathrm{~cm}^{-3}$, which compares well with the observed value of $248 \mathrm{~cm}^{-3}$. Note that this is lower than the observed (Heintzenberg et al., 2000) and modelled (Spracklen et al., 2005a) aerosol number reported when we do not filter out air masses with less than $120 \mathrm{~h}$ since continental contact (see Sect. 1).

GLOMAP's median distribution captures some of the key features of the observed MBL median distribution. Firstly, the model has a bimodal submicrometre distribution, with Aitken and accumulation modes at approximately the correct number concentrations (although modelled Aitken and accumulation modes are smaller than observed.) Secondly, both model and observations show "closed" size distributions at small sizes, with a low probability of particles with diameters less than $20 \mathrm{~nm}$. This observation, which is well captured in the model, has been used to suggest that particle nucleation and subsequent growth to observable sizes is infrequent in the MBL (Heintzenberg et al., 2004).

\subsection{Regional variations in the size distribution}

A comparison of modelled and observed particle number from all four experiments suggests overall good agreement (Fig. 2). However, there are some large differences between the model and observations at a regional level. Figure 3 compares the modelled and observed size distributions for the different field campaigns in Heintzenberg et al. (2004), which have been filtered to reduce continental contamination (see Sect. 4.2). Figure 4 summarises the comparison in terms of the parameters of fitted log-normal modes. To aid comparison with Pierce and Adams (2006), in Fig. 5 we also compare with the unfiltered zonally averaged size distributions originally presented in Heintzenberg et al. (2000) (baseline model 
(a)

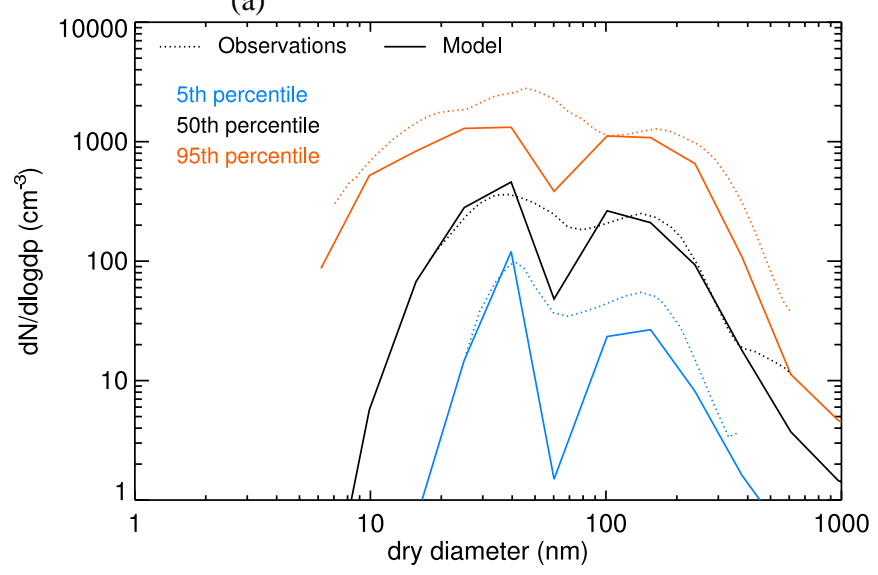

(b)

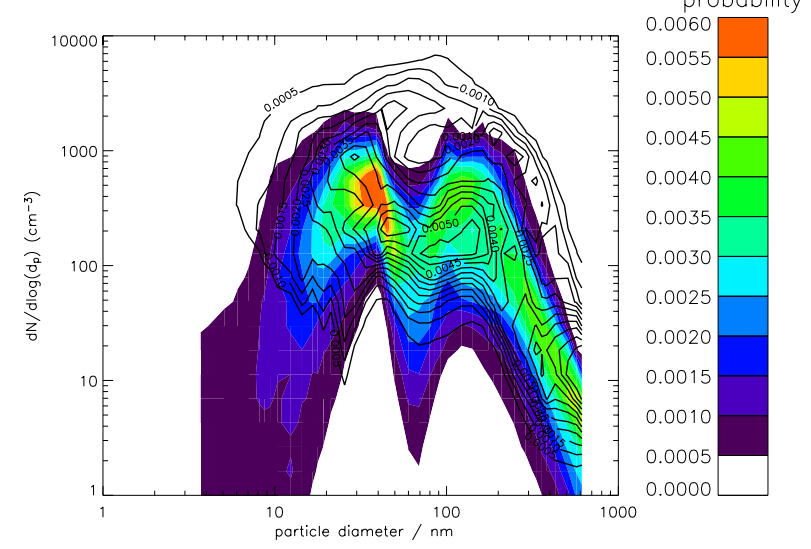

Fig. 2. Comparison of model size dependent number concentrations with the aerosol climatology from Heintzenberg et al. (2004) for all the marine observations detailed in Table 1. Both model and observations are filtered to include only the remote MBL (air masses greater than $120 \mathrm{~h}$ since last continental contact). (a) Sizedependent 5 th, 50th and 95th percentiles of number concentrations for the remote MBL. Solid line is the GLOMAP model and dotted line is aerosol climatology. (b) Comparison of modelled and observed probability distributions of size-dependent number concentrations between 1 and $10^{4} \mathrm{~cm}^{-3}$. Filled colour contours are the GLOMAP model, line contours are the observations. Observed PDFs were generated for 48 logarithmically equal size classes between 3 and $900 \mathrm{~nm}$. GLOMAP distributions have 20 aerosol size sections between about $3 \mathrm{~nm}$ and $25 \mu \mathrm{m}$. To allow a comparison between GLOMAP and observations, GLOMAP distributions are interpolated onto the observed diameters. The PDFs of number concentrations for both observations and GLOMAP were constructed by classifying the number size distributions into 20 equal logarithmically spaced concentration bins between 1 and $10000 \mathrm{~cm}^{-3}$. The number of cases in each concentration bin was divided by the total number of concentrations to give the probability in each bin.

run is the solid black line). As we show below, the binning of observations in latitude bands may hide some interesting differences between the model and observations for the separate regional campaigns.

A clear difference between the model and the observations is the underprediction of Aitken mode number between $45^{\circ} \mathrm{S}$ and $30^{\circ} \mathrm{S}$ by $>50 \%$ (Fig. 5 and Fig. 3, ACE-1). A smaller discrepancy exists between $75^{\circ} \mathrm{S}$ and $45^{\circ} \mathrm{S}$. Model underprediction of total aerosol number at these latitudes has been reported previously (Spracklen et al., 2005a; Easter et al., 2004; Pierce and Adams, 2006). In Spracklen et al. (2005a) we suggested that this was due to a strong seasonal cycle at these latitudes. Observations were generally made during the Southern Hemisphere spring or summer when DMS emissions are large and previous model comparisons have used model annual mean. In this work we only use model results for the same calendar months as the observations and Aitken mode number is still underpredicted by between 30 and $50 \%$.

Recent work by Pierce and Adams (2006) has suggested that ultrafine sea salt has an important impact on submicrometre marine aerosol size distributions. They showed that emission of ultrafine sea salt, particularly with the Martensson et al. (2003) scheme, resulted in significant increases in Aitken mode number between $45^{\circ} \mathrm{S}$ and $75^{\circ} \mathrm{S}$, but only a very minor increase in Aitken mode number between $45^{\circ} \mathrm{S}$ and $30^{\circ} \mathrm{S}$. Their work suggests that the lack of ultrafine sea salt in our model may be responsible for underprediction of Aitken mode number between $45^{\circ} \mathrm{S}$ and $75^{\circ} \mathrm{S}$ but is unlikely to be the cause of the underprediction between $45^{\circ} \mathrm{S}$ and $30^{\circ} \mathrm{S}$. Further work is required to fully explore the role of ultrafine sea salt.

There are other differences between modelled and observed Aitken mode number in other regions (Fig. 3). For example, in ACE-2 (N. Atlantic) the ratio modelled/observed number is 0.06, while it is 7.4 for ACE-Asia (NW Pacific). In both cases the modelled Aitken mode particles are too small. Model Aitken number for ACE-Asia may be overpredicted due to lack of dust aerosol in the model. Dust is a major component of East Asian aerosol outflow and was sampled on a number of occasions during ACE-Asia. Dust aerosol provides additional surface area increasing the fraction of sulfate found in the coarse mode. Tang et al. (2004) showed that downwind of East Asia between 10 and 15\% of sulfate occurs in the supermicrometre mode. For INDOEX/Aerosols99 the model/observed Aitken number ratio is 1.5 , indicating much better agreement at lower latitudes, but again the particles are too small in the model. The model underprediction of Aitken mode size is present at all locations and as a grand average the Aitken mode geometric mean diameter of the pollution-filtered model is $72 \%$ of that observed. This difference equates to the modelled Aitken particle volume being only $37 \%$ of that observed.

The accumulation mode number concentrations are generally in fair agreement, and the model captures some of the observed differences between the different regions. The biases (model divided by observations) in accumulation mode number are: ACE-1 (0.57), ACE-2 (1.1), INDOEX/Aerosols99 (1.1), and ACE-Asia (1.9). The accumulation mode size is 

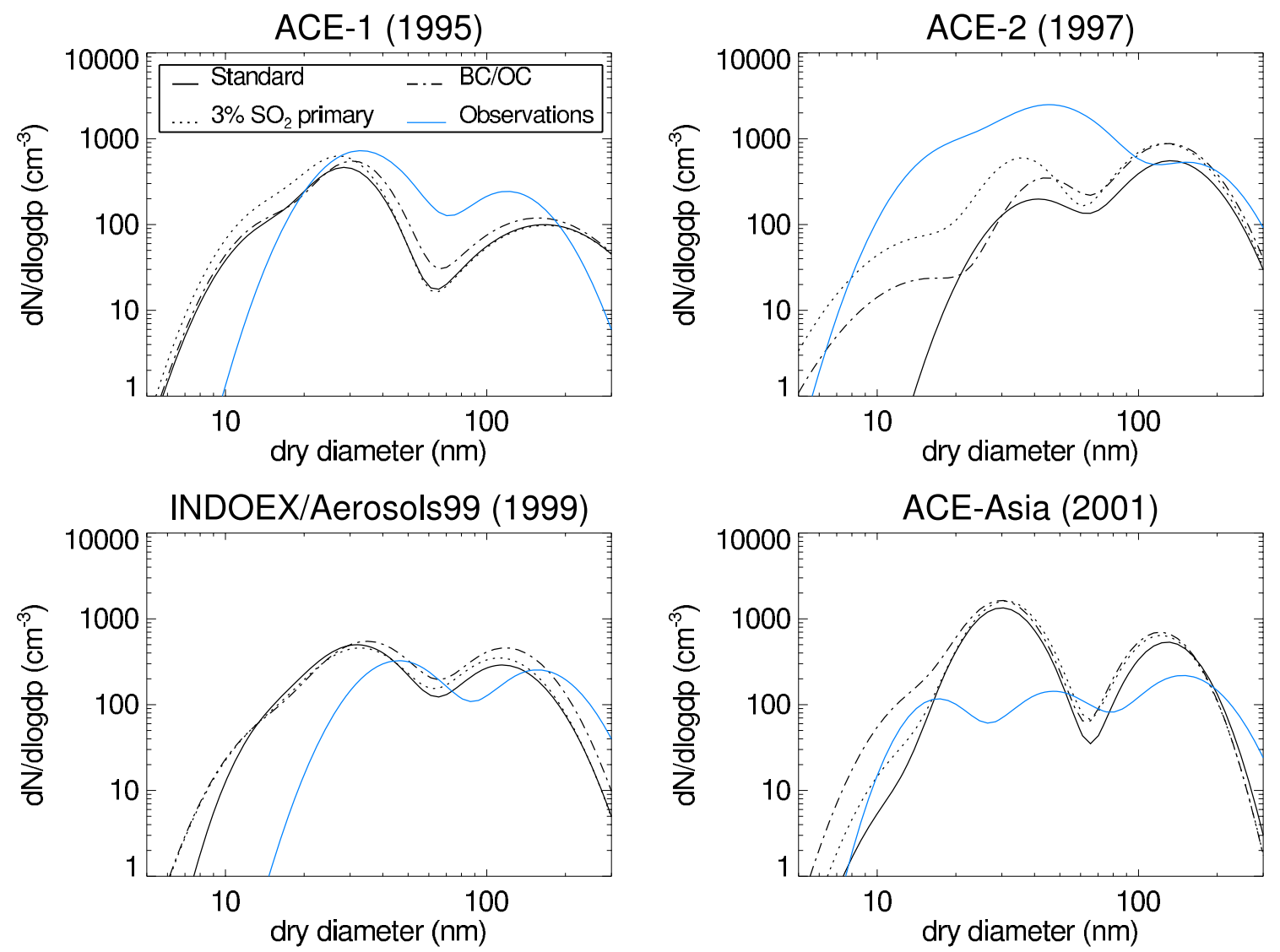

Fig. 3. Comparison of regional MBL log-normal approximations of aerosol number size distributions. The model (black lines) and observations (solid blue line) have been filtered to minimise continental contamination (see Sect. 4.2) and fitted with lognormal modes. Observations are from Heintzenberg et al. (2004). Standard model run includes no primary emissions from anthropogenic sources, $3 \% \mathrm{SO}_{2}$ primary model run includes $3 \%$ of anthropogenic sulfur as particulate sulfate, BC/OC model run includes primary emissions of black carbon and organic carbon.

underpredicted in all regions except for the Southern Ocean (ACE-1). The biases (model divided by observations) are: ACE-1 (1.4), ACE-2 (0.83), INDOEX/Aerosols99 (0.73), and ACE-Asia (0.85).

The model overpredicts Aitken mode number for ACEAsia and INDOEX but underpredicts the size of the mode.

Heintzenberg et al. (2000) reported that both Aitken and accumulation mode diameters are about $25 \%$ bigger in the Northern than the Southern hemispheres. This trend is supported by observations in the field campaigns in Heintzenberg et al. (2004) but is not captured by the model. It is interesting that accumulation mode size is either well predicted or overpredicted by the model in the remote Southern Ocean $\left(75^{\circ} \mathrm{S}-30^{\circ} \mathrm{S}\right)$ whereas it is generally underpredicted in the NH. Particle size in the NH may be larger due to emissions from continental sources (e.g., primary emissions of carbonaceous aerosol or emissions of volatile organic compounds that are oxidised to secondary organic aerosol), which are not included in the baseline model runs presented here. Alternatively differences in cloud processing between hemispheres may influence the activation diameter which is fixed in this model run. In Sects. 5.3 and 8 we explore the effect of anthropogenic primary emissions and of more detailed aerosol activation schemes on the modelled aerosol size distribution.

Another difference between the model and observations is in the minimum in the number-size distribution between the Aitken and accumulation modes (apparent in Fig. 2). The modelled number concentration at the minimum is too low. The deep minimum is caused by the use of a fixed activation diameter $(50 \mathrm{~nm})$ during cloud formation in the model. In reality, this activation diameter varies according to variations in updraft velocity as well as the shape of the particle size distribution. This issue is also connected with the way that the diameter of the observed Aitken and accumulation modes (and the minimum between them) increases from the $5 \%$ to the $50 \%$ to the $95 \%$ percentiles (e.g., the minimum increases as 63,78 and $110 \mathrm{~nm}$ ). That is, particle distributions 

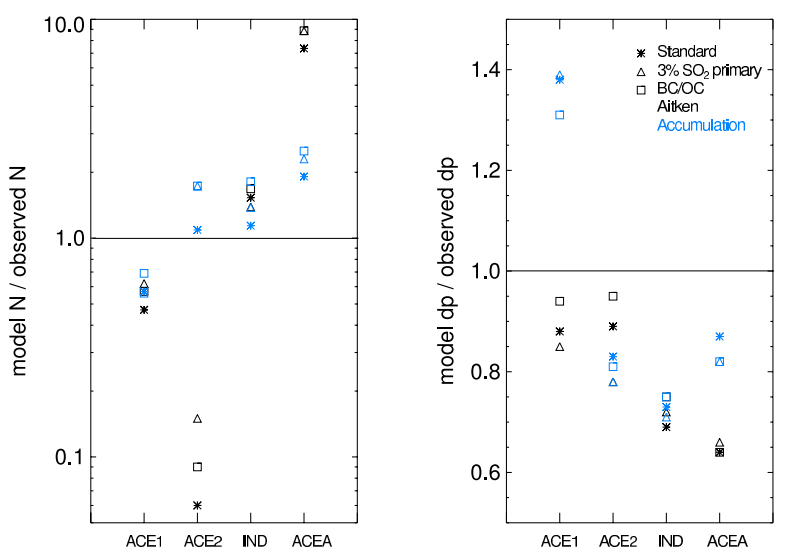

Fig. 4. Comparison of modelled and observed (Heintzenberg et al., 2004) Aitken (black) and accumulation (blue) mode lognormal fit parameters for the four marine experiments (ACE-1, ACE-2, INDOEX/Aerosols99, ACE-ASIA). (a) Model mode number concentration $\left(\mathrm{N}_{\text {model }}\right) /$ Observed mode number concentration $\left(\mathrm{N}_{\text {observed }}\right)$, (b) Model geometric mean diameter $\left(\mathrm{dp}_{\text {model }}\right)$ / Observed geometric mean diameter ( $\left.\mathrm{dp}_{\text {observed }}\right)$. Standard model run includes no primary emissions from anthropogenic sources, $3 \% \mathrm{SO}_{2}$ primary model run includes $3 \%$ of anthropogenic sulfur as particulate sulfate, $\mathrm{BC} / \mathrm{OC}$ model run includes primary emissions of black carbon and organic carbon.

with higher concentrations tend to have larger accumulation modes. The model does not capture this property. These effects are explored in Sect. 8.

\subsection{Effect of anthropogenic aerosol on the size distribution}

In section 5.2 we showed that the model greatly underpredicts the concentration of Aitken mode particles over the $\mathrm{N}$. Atlantic (based on a comparison with observations from ACE-2). Although the analysis included only airmasses that were more than $120 \mathrm{~h}$ from land, it is still possible that anthropogenic material contributes to the particle loading. Before examining the effect of anthropogenic emissions on the size distribution, we quantify the effectiveness of the $120 \mathrm{~h}$ cut-off in filtering out continental contamination. We do this by using the model to track separate anthropogenic (anth) and natural (nat) sulfur tracers. $\mathrm{SO}_{2}$ (anth) is emitted directly from anthropogenic combustion sources (including 3\% as primary sulfate particles) and $\mathrm{SO}_{2}$ (nat) is derived from DMS oxidation products and directly from volcanic emissions. Through gas phase oxidation these two tracers produce $\mathrm{H}_{2} \mathrm{SO}_{4}$ (anth) and $\mathrm{H}_{2} \mathrm{SO}_{4}$ (nat). We then track separate anthropogenic and natural particulate components formed after either nucleation or condensation of the two different $\mathrm{H}_{2} \mathrm{SO}_{4}$ tracers or aqueous phase oxidation of the two different $\mathrm{SO}_{2}$ tracers.

Figure $6 \mathrm{a}$ and $\mathrm{b}$ show the contribution of natural and anthropogenic sulfate to the total aerosol mass in the boundary layer with and without the $120 \mathrm{~h}$ filter, respectively. The unfiltered results show that between 60 and $90 \%$ of the N. Atlantic particulate sulfate is anthropogenic in origin. In the SH oceans generally less than $20 \%$ of surface model sulfate is anthropogenic in origin. Earlier model studies have found that over $\mathrm{NH}$ oceans up to $80 \%$ of surface sulfate in anthropogenic in origin whereas this is generally less than $20 \%$ over most of the SH oceans (Chin et al., 1996; Koch et al., 1999; Chin et al., 2000; Rasch et al., 2000). Including the age filter has little influence on the extent to which anthropogenic sources impact on MBL aerosol. The average fraction of anthropogenic sulfate across the aerosol size distribution is shown for the geographic regions covered by each field campaign in Fig. 6c. A fraction in excess of 70\% is calculated across the entire size spectrum for ACE-2 and ACE-Asia regions both with and without the age filter. The strong continental influence on aerosol across each of these regions may explain why the model fails to accurately predict Aitken mode concentrations. The inclusion of other continental material such as carbonaceous aerosol and condensable organics may lead to a better agreement between model and observations.

ACE-1 stands out from Fig. 6 as being the campaign from which observations best characterised natural aerosol processes. Nevertheless, our model suggests there was probably still a substantial continental influence on air sampled across Cape Grim, even when excluding air masses aged less than $120 \mathrm{~h}$ since contact with land. From these model results it appears that the majority of the remote marine air sampled across each campaign is likely to have been contaminated with continental material. Figure 6 shows that there are few regions of the Northern Hemisphere ocean where the influence of anthropogenic sulfate on marine aerosol is negligible.

5.4 Effect of primary anthropogenic emissions on MBL size distributions

The baseline model run presented in Sects. 5.1 and 5.2 includes anthropogenic $\mathrm{SO}_{2}$ emissions but no emissions of primary anthropogenic particles. Here we investigate the contribution of anthropogenic primary emissions to MBL size distributions and explore to what extent they may explain discrepancies between model and observations as outlined in Sects. 5.1 and 5.2.

\subsubsection{Effect of primary sulfate emissions}

Spracklen et al. (2005a) and Adams and Seinfeld (2002) have shown that primary anthropogenic sulfate particles can greatly increase continental boundary layer $\mathrm{CN}$ number, and may also affect particle concentrations over oceanic regions downwind. In Spracklen et al. (2005b) we showed in particular that N Atlantic MBL CN concentrations could be increased by between 100 and $300 \%$ by such emissions. As in Spracklen et al. (2005b) we follow the approach of Adams 

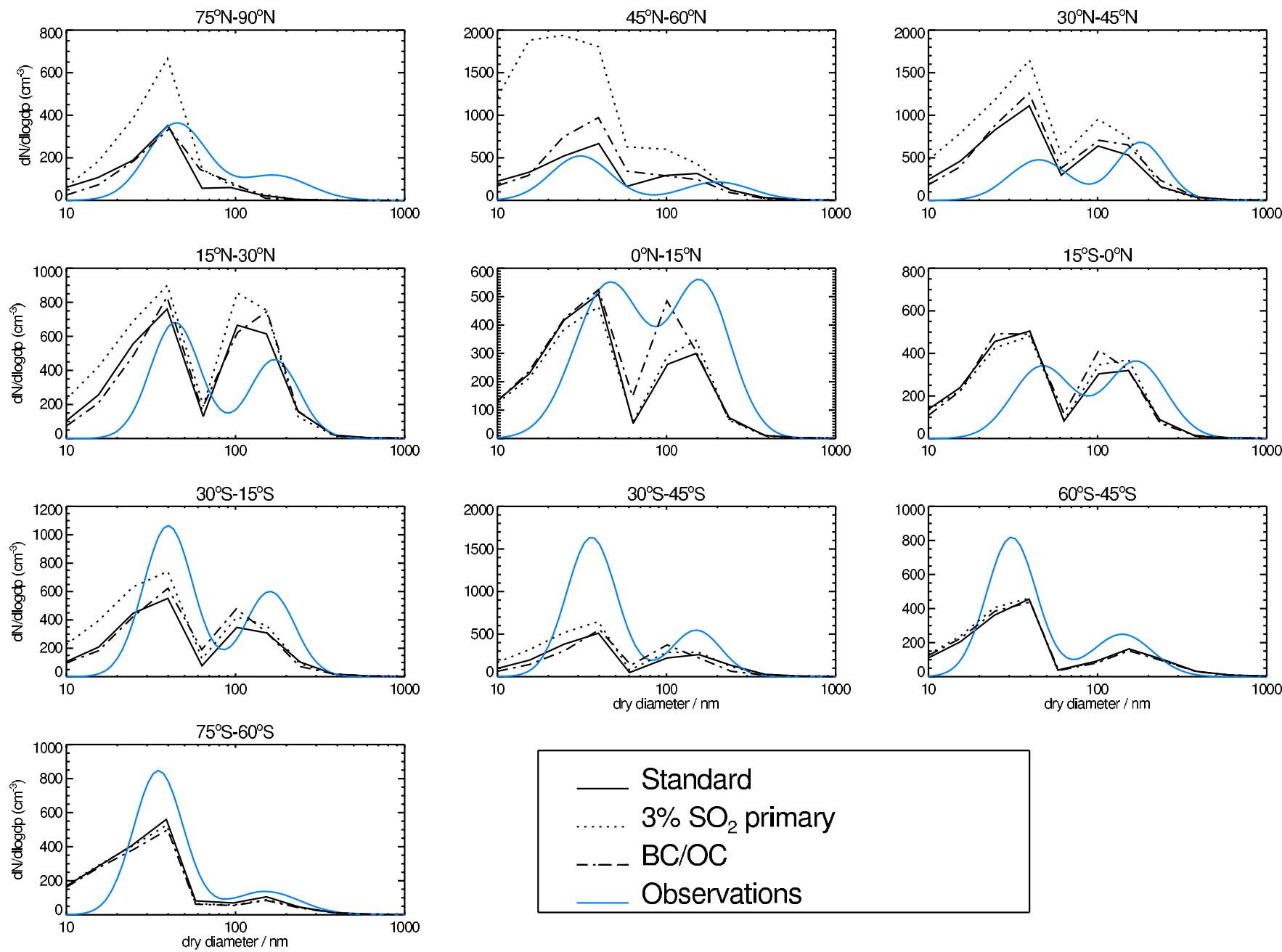

Fig. 5. Comparison of zonal MBL aerosol number size distributions. Observations are from Heintzenberg et al. (2000). Model output is for the $15^{\circ}$ latitude $\mathrm{x} 15^{\circ}$ longitude grid cells defined by Heintzenberg et al. (2000) and the results have not been filtered to reduce continental contamination. Standard model run includes no primary emissions from anthropogenic sources, $3 \% \mathrm{SO}_{2}$ primary model run includes $3 \%$ of anthropogenic sulfur as particulate sulfate, $\mathrm{BC} / \mathrm{OC}$ model run includes primary emissions of black carbon and organic carbon.

and Seinfeld (2003) and assume 3\% of anthropogenic sulfur is emitted as primary particles with two lognormal modes with geometric mean diameters of 10 and $70 \mathrm{~nm}$ and standard deviations of 1.6 and 2.0, respectively. Fifteen percent by mass of the primary particles is assumed to be emitted in the small mode and the remainder in the large mode.

The effect of these anthropogenic primary emissions on modelled Aitken and accumulation mode number and size is summarised in Fig. 4 as triangles.

Figures 3 and 5 show the effect of including primary emissions (dotted line) on regional and zonal number size distributions. When we do not filter out continental air masses including primary emissions causes a large increase in model Aitken mode between $45^{\circ} \mathrm{N}$ and $60^{\circ} \mathrm{N}$ resulting in an overprediction of Aitken mode number here by about a factor of 4. The impact of primary sulfate emissions is smaller when we filter out continental airmasses (Fig. 4). ACE-Asia and INDOEX modelled median number increase by about $25 \%$ and ACE- 2 concentrations by about $50 \%$. ACE- 2 95th percentile number increases by a factor of 2.5. However, ACE-2 Aitken mode number is still greatly underpredicted even with primary emissions.

Including primary emissions of anthropogenic sulfate (with the assumptions on mode size and emission rate made here) has relatively little impact on the size of the Aitken mode and does not help to explain model underprediction of mode diameter. 
(a)
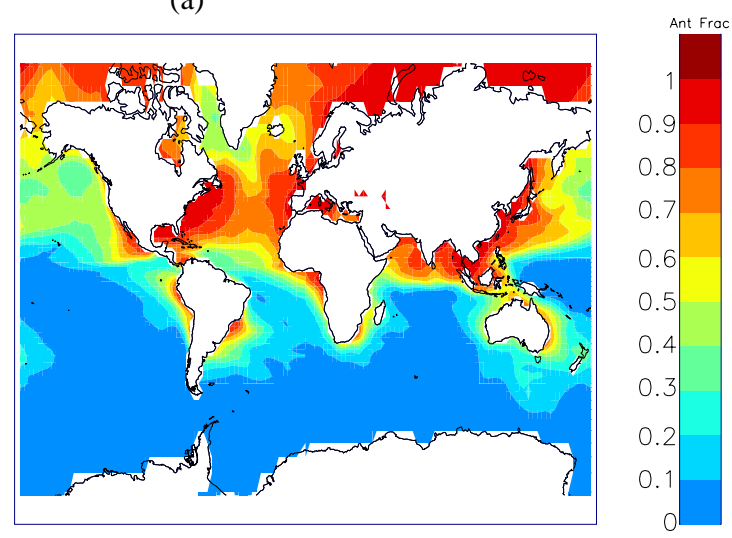

(b)
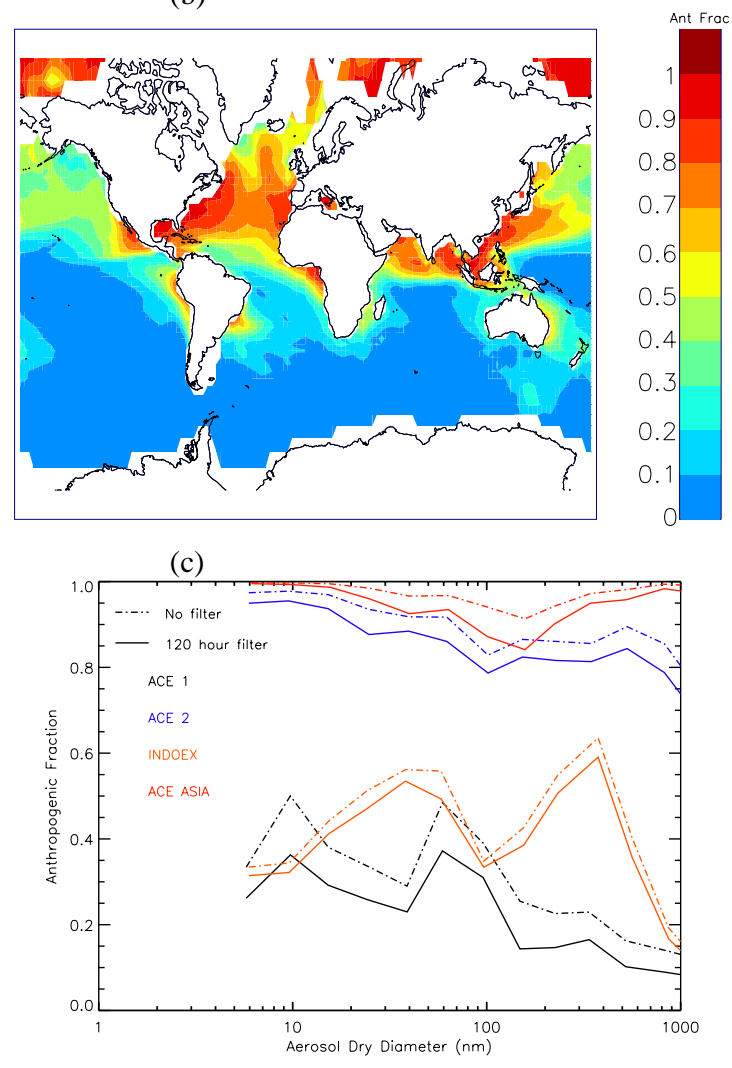

Fig. 6. Contribution of anthropogenic sources to the total burden of submicrometre sulfate as an average for July and December 1995. (a) Global distribution using all model data without filtering. (b) Global distribution after filtering to remove air that is less than $120 \mathrm{~h}$ from land. (c) Contribution of anthropogenic sulfur to the modelled aerosol size distribution for the geographic regions covered by each field campaign when including and excluding the $120 \mathrm{~h}$ filter. Results are shown as an average for June and December 1995.

5.4.2 Effect of industrial and biomass burning black and organic carbon

$\mathrm{BC}$ and $\mathrm{OC}$ particles have also been observed at remote MBL sites (Heintzenberg and Bigg, 1990). During the Joint
Global Ocean Flux Study (JGOFS) cruises between Nova Scotia and the Canary Islands during September-October 1992, Van Dingenen et al. (1995) observed high concentrations of carbonaceous aerosols up to about $600 \mathrm{~km}$ from the continents. We examine the potential influence of $\mathrm{BC}$ and OC particles on the MBL aerosol distributions. The effect on regional Aitken and accumulation mode aerosol is summarised in Fig. 4 as squares.

$\mathrm{BC}$ and $\mathrm{OC}$ emissions increase grand average median aerosol number by about $40 \%$ (from $250 \mathrm{~cm}^{-3}$ to $350 \mathrm{~cm}^{-3}$ ) and grand average 95th percentile number by $75 \%$ (from $1370 \mathrm{~cm}^{-3}$ to $2390 \mathrm{~cm}^{-3}$ ) even with the $120 \mathrm{~h}$ filter. These emissions result in a better comparison with the observed 95th percentile concentration of $2380 \mathrm{~cm}^{-3}$. However, the success of the model in capturing regional variations in Aitken and accumulation mode properties is limited (Fig. 3 and 4). In the N. Atlantic (ACE-2) the inclusion of BC/OC emissions has a negligible effect on the significant underprediction of Aitken mode concentration, with the ratio modelled/observed changing from 0.06 to 0.09 . Aitken mode concentrations were already overpredicted by a factor 7 in the NE Pacific even without anthropogenic primary emissions, and inclusion of $\mathrm{BC} / \mathrm{OC}$ increases that overprediction to a factor 9. There is a slight improvement for the ACE-1 region in the Southern Ocean where anthropogenic BC and OC improve the underprediction of Aitken mode number from 55\% to $40 \%$.

The effect of anthropogenic $\mathrm{BC}$ and $\mathrm{OC}$ on accumulation mode number is also mixed. There is a slight improvement for ACE-1 but mode number is now overpredicted by about a factor 2 for ACE-2 and ACE-Asia, where good agreement was obtained in the baseline simulation. The mode diameter of the accumulation mode is hardly affected or even made worse by the primary emissions.

\subsubsection{Discussion of the effect of anthropogenic primary emissions}

This comparison has identified a number of significant discrepancies between modelled and observed particle size distributions in the MBL. We have shown that it is difficult to filter out anthropogenic (or continental) influences on aerosol simply based on the time that air has spent away from continental sources. This means that model-observation discrepancies may be due in large part to uncertainties in continental emissions rather than marine aerosol emissions and processes. Thus, it is difficult, based on these datasets, to evaluate our understanding of clean remote regions. Rather, our model-observation comparison becomes a test also of our understanding of continental aerosol processes.

Our model, including natural and anthropogenic emissions, underpredicts Aitken mode concentrations by more than factor 9 in the N. Atlantic (ACE-2) but overpredicts by a similar amount over the NW Pacific (ACE-Asia). Superfine sea spray emission is a possible explanation for the 
underprediction over the Atlantic, but the study of Pierce and Adams (2006) suggests only a $20 \%$ effect at these latitudes. Another possible explanation for the underprediction is the lack of aerosol nucleation in the lower layers of the model atmosphere. We have shown that Atlantic CN concentrations could be enhanced by up to a factor 10 by this mechanism (Spracklen et al., 2006), although the predictions for marine regions remain to be tested. An ultrafine mode with diameter $19 \mathrm{~nm}$ and median concentration of $248 \mathrm{~cm}^{-3}$ $\left(1866 \mathrm{~cm}^{-3}\right.$ for the 95 th percentile) is apparent in the observations during ACE-2 but is much less obvious during other campaigns. The complete lack of this mode in the model suggests we are missing a significant source of ultrafine particles in the lower atmosphere over the NE Atlantic. Including primary anthropogenic emissions does produce an ultrafine mode in the model but with low number concentrations (median number of $30-40 \mathrm{~cm}^{-3}$ for ACE-2). The ultrafine mode may be attributable to local particle formation in the lower atmosphere which could contribute to total particle concentrations. ACE- 2 observations are from a coastal station in Portugal and therefore could be also influenced by coastal nucleation (O'Dowd et al., 1999). A further explanation for the underprediction in the N. Atlantic could be that emissions inventories for anthropogenic primary particles (BC and $\mathrm{OC}$ ) are too low in terms of particle number at Aitken mode sizes. In addition, our treatment of BC and OC aerosol as hydrophilic upon emission will likely increase the efficiency at which this aerosol is scavenged.

\section{Free tropospheric number-size distribution}

We have shown that the model consistently underpredicts the size of the Aitken mode in the MBL. This could be a result of the model underpredicting the FT particle size. FT aerosol is entrained into the MBL and is the main source of the Aitken mode. Here we compare modelled FT number-size distributions against observations to evaluate to what extent this is the case.

Clarke and Kapustin (2002) averaged observations from six aircraft flights of the PEM-Tropics B campaign over the tropical Pacific Ocean between $20^{\circ} \mathrm{S}$ and $20^{\circ} \mathrm{N}$ during March and April 1999. Figure 7a and b show a comparison of observed and modelled aerosol vertical profiles. Both model and observations clearly show a monomodal distribution in the FT (in contrast to the multi-modal distribution observed and modelled in the MBL due to cloud processing). As air descends from about $5 \mathrm{~km}$ altitude towards the MBL, the particles grow (through coagulation and condensation of vapours) and particle number falls (due to coagulation). While modelled particle number and size shows the same trends with altitude as observed, it is clear from Fig. 7a and $b$ that modelled growth of particles during descent is less than observed. This can also be seen in Fig. 7c, which compares modelled and observed number-size distributions in the lower FT. Observations are from a variety of different measurement campaigns and all show a monomodal distribution with number peak dry diameter at between 50 and $80 \mathrm{~nm}$, somewhat larger than the modelled peak at around $40 \mathrm{~nm}$. These comparisons suggest that insufficient particle growth in the FT produces FT particles that are too small when they are entrained into the MBL. Heald et al. (2005) suggests that a large fraction of FT aerosol mass is secondary organic from the oxidation of long lived volatile organic compounds. The model runs do not include condensation of secondary organic aerosol. Our results therefore suggest that long-range transport of continental organic compounds could impact the remote MBL aerosol. Further work is needed to confirm this hypothesis. An additional contribution to underestimated growth maybe be due to the problems of representing subgrid scale growth in the global model.

\section{Variability of MBL aerosol}

The variability of MBL aerosol was investigated by Heintzenberg et al. (2004) in order to understand the physical processes that control the aerosol properties. There are two aspects to the variability of MBL aerosol: the spread of particle concentrations about the median and the temporal variability.

\subsection{Particle concentration variability}

Figure 8 compares the variability of observed and modelled aerosol about the median for the four experiments combined. It shows the frequency of occurrence of different particle concentrations relative to the median after applying the $120 \mathrm{~h}$ filter. The results show that the model correctly captures the frequency of occurrence of particle concentrations greater than the median but tends to overpredict the occurrence of concentrations much less than the median. The same result is apparent in Fig. 2: for particle diameters greater than about $40 \mathrm{~nm}$ the model 5th percentile is lower than the observed 5 th percentile. Part of this discrepancy at very low $\mathrm{N} / \mathrm{N}_{\text {med }}$ may be due to bad counting statistics at low number concentrations as described in Sect. 3. This will lead to a high bias in the observations. The excessive occurrence of relatively low particle concentrations suggests that the model's removal processes are too effective. It needs to be borne in mind that this analysis of the grand average variability may obscure regional differences.

\subsection{Temporal variability}

Heintzenberg et al. (2004) discussed the persistence of MBL aerosol in the Southern Ocean and how it contrasts with that of a continental site. The observations at the continental site show an obvious diurnal cycle but no diurnal cycle is present at the marine site. Figure 9 compares the persistence of GLOMAP and the observations at the remote marine site 
(a)

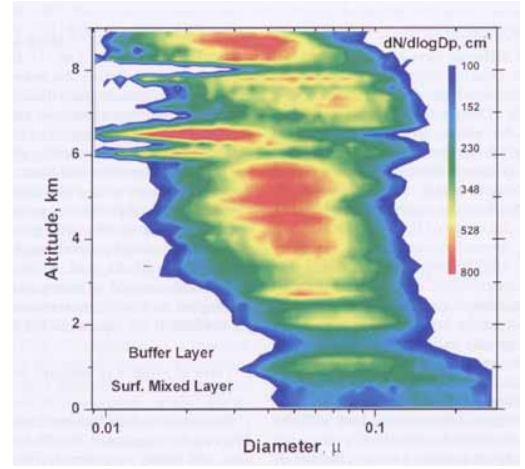

(b)

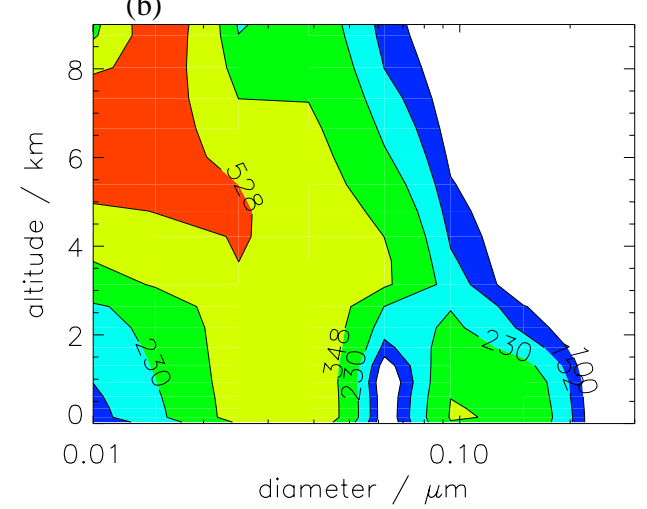

(c)

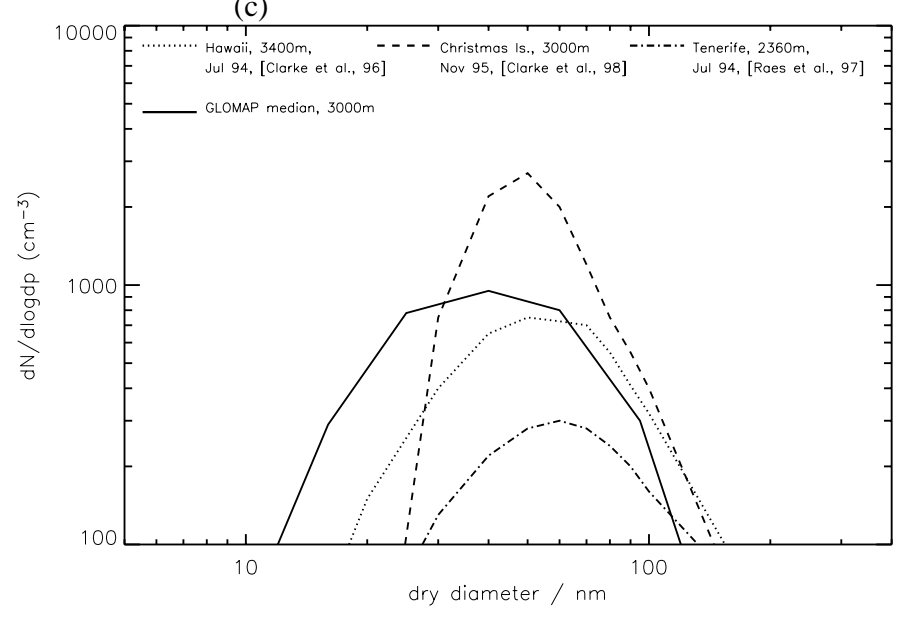

Fig. 7. Number size distribution (at ambient temperature and pressure) in the tropical Pacific. (a) Observations from six PEM-Tropics B profiles between $20^{\circ} \mathrm{S}$ and $20^{\circ} \mathrm{N}$ (Clarke and Kapustin, 2002) Contours are $\mathrm{dN} / \mathrm{d} \log \mathrm{D}_{p}\left(\mathrm{~cm}^{-3}\right)$. (b) GLOMAP model mean number size distribution for 15 March-15 April 1999 averaged over $20^{\circ} \mathrm{S}-20^{\circ} \mathrm{N}, 210^{\circ} \mathrm{E}-270^{\circ} \mathrm{E}$. (c) Comparison of observed and modelled number size distributions in the lower free troposphere. Solid line shows the GLOMAP median distribution at $3 \mathrm{~km}$ altitude averaged over the same geographic locations as in Fig. 2. Observations are from a variety of campaigns at altitudes between 2.4 and $3.4 \mathrm{~km}$.

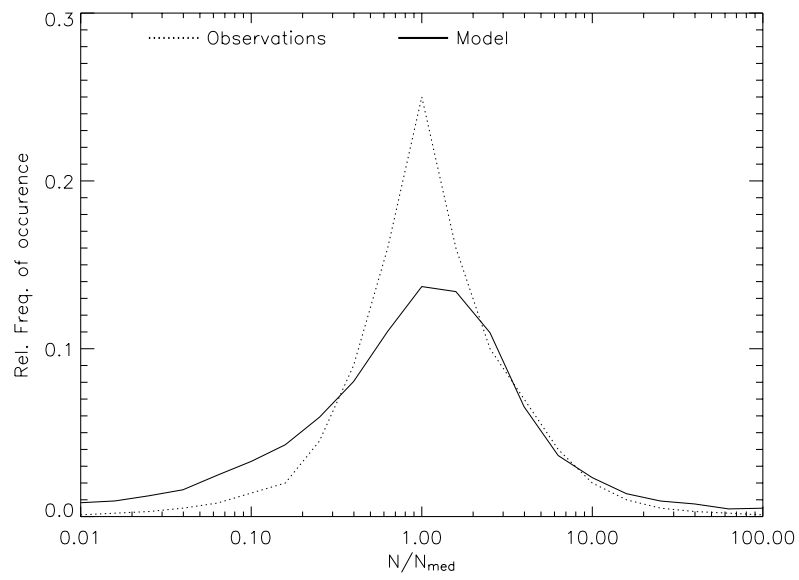

Fig. 8. Variability of size averaged and median normalised number concentrations in the MBL. Solid line is the GLOMAP model and dashed line is the average of all marine experiments from Heintzenberg et al. (2004). The number at each measurement diameter and model size bin were normalised with the respective median concentration. These normalised concentrations were then placed in 21 geometrically spaced bins spanning between 0.01 and 100 times the median concentration.

in the Southern Ocean. The model and observations have several features in common: e.g., the smallest particles have the least persistence; and a lack of a diurnal cycle for any size class in the MBL. The short persistence of small particles is not surprising. It indicates that there is no steady source of small particles and that, when small particles do exist, their persistence is limited by rapid coagulation. The presence of a diurnal cycle at the continental site suggests that the smallest continental particles have a local photochemical source either in or just above the BL. The lack of such a cycle at the marine site suggests that such nucleation is uncommon in the Southern Ocean MBL. Particle formation in the UT will certainly have a diurnal cycle driven by photochemistry, but the long transport time from the UT to the BL will tend to smooth this out. In GLOMAP, we include only binary $\mathrm{H}_{2} \mathrm{SO}_{4}-\mathrm{H}_{2} \mathrm{O}$ particle nucleation, which does not produce particles in the $\mathrm{BL}$ (due to the strong temperature dependence of this mechanism) and explains the lack of a diurnal cycle modelled number-size distribution. The good comparison between modelled and observed persistence at this site suggests that the model is correctly calculating the source of secondary particles to the MBL (i.e., from the FT) and would appear to rule out a local particle formation source. Further work needs to determine whether there are regional differences in the importance of particle formation. 


\section{Sensitivity to in-cloud aerosol activation schemes}

In the baseline model runs all aerosol greater than $50 \mathrm{~nm}$ dry diameter is activated into cloud droplets when low clouds are present. Here we explore the impact of including a physically based aerosol activation scheme. Figure 10 shows a comparison of size-dependent percentiles of number concentration simulated using the fixed activation diameter scheme and the NS03 scheme. For NS03, we show results for two fixed updraught speeds and a run with a random updraught speed between two limits.

To minimise the computational expense of multiple model runs for an entire year, we limit model output for the sensitivity tests to a 10 day period in January and a 10 day period in July. Comparisons of this shortened model output (Fig. 10a) with that for an entire model year (Fig. 2) shows that we produce number concentrations in any model bin to typically within $\pm 30 \%$.

The use of a variable activation scheme with a constant updraft speed reduces the depth of the minimum in the number size distribution between the Aitken and accumulation modes. This reduction occurs because the NS03 scheme permits the different aerosol distributions to activate with different efficiencies, leading to the prediction of a range of activation diameters. This range smoothes out the minimum between the Aitken and accumulation modes and results in better agreement with the observations. The use of a random distribution of updraft velocities further reduces the minimum between the Aitken and accumulation modes. However, we note that using the NSO3 scheme reduces the modelled accumulation mode number concentration giving a worse comparison with observations.

In the observational data, the mean diameter of the accumulation mode and the diameter of the minimum between the Aitken and accumulation modes increases from the 5th to the 50th to the 95th percentile. With the fixed diameter of activation, GLOMAP is unable to capture this shift; the accumulation mode occurs in the same position for all three percentiles. When the NS03 scheme is used, the mean diameter of the accumulation mode is shifted to larger sizes as the percentile increases. This occurs because the NS03 scheme is able to capture the feedback between particle number and the activation diameter: when particle number is small, there are few sites onto which water vapour can condense, thus the maximum supersaturation attained is large, and the corresponding activation diameter is small. Likewise, the maximum supersaturation is suppressed and the activation diameter is large when particle concentrations are high. This finding highlights the coupling between the particle size distribution and cloud processes.

The NS03 scheme combined with the updraft speeds chosen here makes the comparison of model 5 th percentile with observations worse. This is especially true for the Aitken mode which is reduced both in size and number. Particle wet removal in our model appears to be too effective resulting in

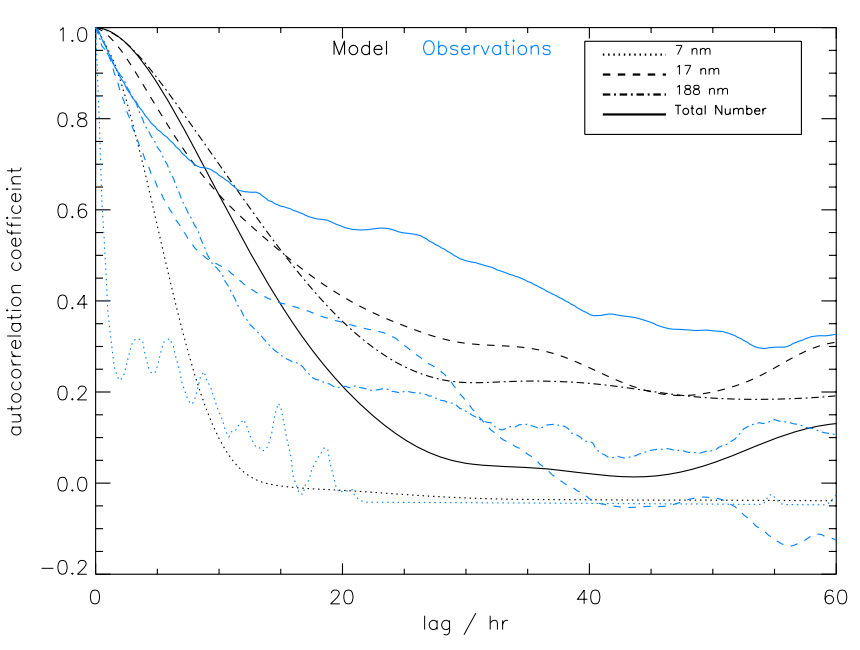

Fig. 9. Modelled and observed (Heintzenberg et al., 2004) autocorrelation coefficients in the remote MBL at Cape Grim $\left(40.8^{\circ} \mathrm{S}\right.$, $\left.144.7^{\circ} \mathrm{E}\right)$ for different size particles and for total number concentrations for time lags between 0 and $60 \mathrm{~h}$. Model results are for the nearest model grid square whose land use is defined as $100 \%$ ocean.

too many occurrences of low particle concentrations in the model (Fig. 8). With the standard fixed activation scheme low particle concentration has no impact on the size of particles activated. With the NSO3 scheme low particle concentrations result in particle activation down to very small diameters which impacts Aitken mode size and number.

\section{Conclusions}

Recent compilations of marine boundary layer aerosol observations (Heintzenberg et al., 2000, 2004) have allowed a detailed evaluation of a global 3-D sectional aerosol microphysics model against MBL aerosol statistics. We extend previous comparisons of observed and model particle number concentrations (Spracklen et al., 2005a) to include particle number size distributions, probability distributions, and temporal persistence of different size particles. The observation datasets allow us to compare global and regional marine aerosol properties. Heintzenberg et al. (2000) bins aerosol observations by $15^{\circ}$ latitude bands. Heintzenberg et al. (2004) compiles observations from 5 different field experiments (ACE-1, ACE-2, INDOEX/Aerosols99, ACEAsia) in four different oceans. To minimise contamination from continental sources this database excludes data with less than $120 \mathrm{~h}$ travel time from last contact with land.

Our initial model simulations assume that MBL aerosol comprises solely of sulfate and sea salt and activation of aerosol particles into cloud droplets occurs at a fixed size. We then explore the impact of primary continental particle 


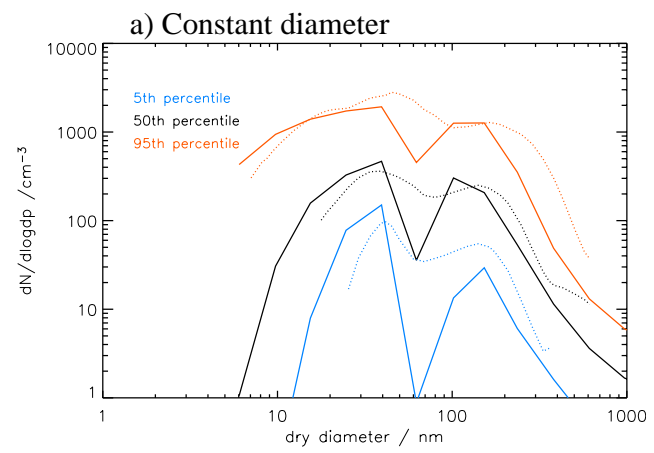

b) Updraft $=0.15 \mathrm{~ms}^{-1}$

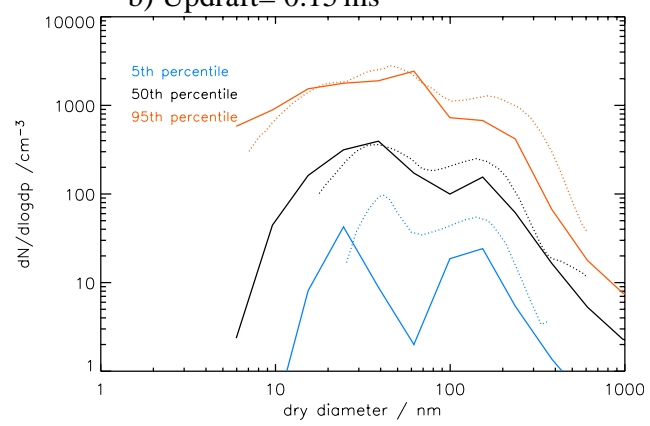

c) Updraft $=0.3 \mathrm{~ms}^{-1}$

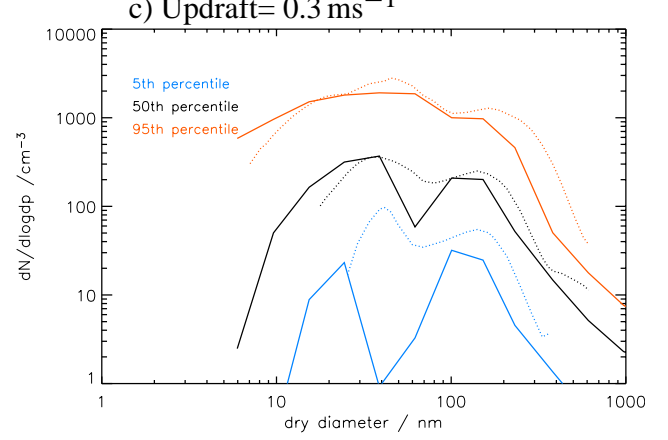

d) Updraft $=0.1-0.3 \mathrm{~ms}^{-1}$

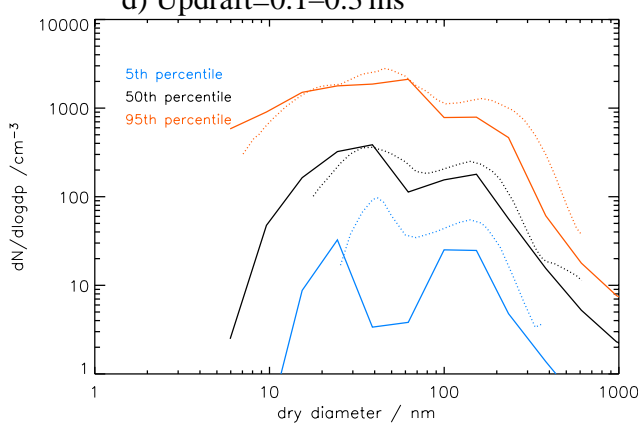

Fig. 10. Comparison of GLOMAP aerosol size distributions for January and July 1996 (solid) with observational data (dotted) from Heintzenberg et al. (2004). Both model and observational data is filtered to minimise continental influence ( $>120 \mathrm{~h}$ since land). Plots show the model data using (a) a constant diameter of activation (of $50 \mathrm{~nm}$ ) and a variable activation diameter, produced using the NS03 activation scheme assuming an updraft velocity of (b) $0.15 \mathrm{~ms}^{-1}$, (c) $0.3 \mathrm{~ms}^{-1}$ and (d) $0.1-0.3 \mathrm{~ms}^{-1}$. emissions and a more detailed treatment of aerosol activation on modelled MBL aerosol.

The model (with sulfate and sea salt aerosol and fixed activation diameter) simulates realistic global mean Aitken and accumulation mode number. Key aspects of global mean remote MBL aerosol distributions - a bimodal distribution with "closed" size distribution at small particle diameters - are accurately captured by the model. "Closed" size distributions suggest that particle nucleation in the MBL is a rare occurrence. In addition we compared model and observed particle persistence in the Southern Ocean MBL, both of which showed no diurnal cycle. In the model this is due to the binary homogeneous $\mathrm{H}_{2} \mathrm{SO}_{4}-\mathrm{H}_{2} \mathrm{O}$ nucleation scheme predicting particle formation solely in the cold UT. Transport time from the UT to BL smoothes out the diurnal cycle in the UT before entrainment into the BL.

Our model is less capable of capturing observed regional variations in aerosol number and size distributions. Observed Aitken mode number is up to a factor of 3 higher than in the model between $75^{\circ} \mathrm{S}$ and $30^{\circ} \mathrm{S}$, a factor of 10 higher than in the model in the $\mathrm{N}$ Atlantic and a factor of 7 lower than the model in the NW Pacific. The work of Pierce and Adams (2006) suggests that ultrafine sea spray may only contribute to part of the underprediction of Aitken mode number in our model. An alternative explanation may be underprediction of particle nucleation in the lower atmosphere over certain areas of the ocean. Further work is required to establish whether different nucleation mechanisms result in more realistic regional representation of Aitken mode number without impacting aerosol properties (closed size distributions and temporal persistence) which are well modelled with the current nucleation scheme.

Our model underpredicts "grand average" Aitken mode geometric mean diameter by $28 \%$ and accumulation mode geometric mean diameter by $15 \%$. Comparison of model and observed FT size distributions suggests that some of the underprediction of Aitken mode size is due to particles not growing sufficiently in the FT before they are entrained into the MBL. This may be due to lack condensable gases, other than sulfuric acid, in our model. The emission of primary carbonaceous aerosol does little to improve modelled Aitken mode or accumulation mode size. Further work is required to investigate the role of secondary organic aerosol which has recently been suggested to contribute greatly to FT aerosol mass (Heald et al., 2005).

Model Aitken mode size is also controlled by the activation diameter of aerosol particles into cloud droplets. Baseline model runs assume a fixed activation diameter of $50 \mathrm{~nm}$. Including a more sophisticated aerosol activation scheme (Nenes and Seinfeld, 2003) improves some aspects of modelled aerosol size distributions. Variable activation diameter results in a more realistic minimum between Aitken and accumulation mode and allows the model to capture feedbacks between aerosol number and activation size. In comparison with observed 5th, 50th and 95th percentiles this allows 
the model to capture the observed increase in accumulation mode size with increasing aerosol number.

The underprediction of accumulation mode size in the MBL is important for calculations of cloud drop number. The importance of this underestimation can be illustrated by considering its effect on the predicted cloud drop number. The Nenes and Seinfeld (2003) parameterisation predicts the median observed distribution to have an average cloud droplet number concentration (CDN) at cloud base of $207 \mathrm{~cm}^{-3}$, but the average $\mathrm{CDN}$ concentration calculated from the model data is just $130 \mathrm{~cm}^{-3}$ (using an updraft velocity from $0.5-$ $5.0 \mathrm{~ms}^{-1}$ ). Some models avoid this underestimation by specifying a minimum aerosol concentration in remote regions in the calculation of CDN, but the forcing calculated is then sensitive to the minimum chosen.

Emissions of primary particles from anthropogenic sources contribute greatly to model MBL aerosol. When we do not filter out air masses with continental character primary emissions can cause a large increase to both Aitken and accumulation mode number. We explore the impact of anthropogenic sulfate on MBL aerosol. In the North Atlantic between 60 and $90 \%$ of sulfate mass across the size range is anthropogenic in origin. This work suggests that even if a back trajectory analysis is used to filter out continental contamination, the North Atlantic is not a good location to study natural aerosol processes many of which will still be dominated by anthropogenic emissions.

Acknowledgements. Grant support from the NERC UK-SOLAS programme and the NERC Universities Global Atmospheric Modelling Programme (UGAMP) is acknowledged.

Edited by: U. Lohmann

\section{References}

Adams, P. and Seinfeld, J.: Predicting global aerosol size distributions in general circulation models, J. Geophys. Res.-Atmos., 107, 4370, doi:10.1029/2001JD001010, 2002.

Adams, P. and Seinfeld, J.: Disproportionate impact of particulate emissions on global cloud condensation nuclei concentrations, Geophys. Res. Lett., 30(5), 1239, doi:10.1029/2002GL016303, 2003.

Andres, R. and Kasgnoc, A.: A time-averaged inventory of subaerial volcanic sulfur emissions, J. Geophys. Res.-Atmos., 103, 25 251-25 261, 1998.

Bates, T., Huebert, B., Gras, J., Griffiths, F., and Durkee, P.: International Global Atmospheric Chemistry (IGAC) project's first Aerosol Characterization Experiment (ACE 1): Overview, J. Geophys. Res.-Atmos., 103, 16 297-16318, 1998a.

Bates, T., Kapustin, V., Quinn, P., Covert, D., Coffman, D., Mari, C., Durkee, P., De Bruyn, W., and Saltzman, E.: Processes controlling the distribution of aerosol particles in the lower marine boundary layer during the First Aerosol Characterization Experiement (ACE 1), J. Geophys. Res.-Atmos., 103, 1636916383, 1998b.
Bates, T., Quinn, P., Coffman, D., Johnson, J., Miller, T., Covert, D., Wiedensohler, A., Leinert, S., Nowark, A., and Neususs, C.: Regional physical and chemical properties of the marine boundary layer aerosol across the Atlantic during Aerosols99: An overview, J. Geophys. Res.-Atmos., 106, 20 767-20 782, 2001.

Bates, T. S., Coffman, D., Covert, D. S., and Quinn, P.: Regional marine boundary layer aerosol size distributions in the Indian, Atlantic, and Pacific Oceans: A comparison of INDOEX measurements with ACE-1, ACE-2, and Aerosols99, J. Geophys. Res.-Atmos., 2002.

Benkovitz, C., Scholtz, M., Pacyna, J., Tarrasón, L., Dignon, J., Voldner, E., Spiro, P., Logan, J., and Graedel, T.: Global gridded inventories of anthropogenic emissions of sulfur and nitrogen, J. Geophys. Res.-Atmos., 101, 29 239-29 253, 1996.

Bigg, E., Gras, J., and Mossop, D.: Wind-produced submicron particles in the marine atmosphere, Atmos. Res., 36, 55-68, 1995.

Bigg, E., Leck, C., and Tranvik, L.: Particulates of the surface microlayer of open water in the central Arctic Ocean in summer, Mar. Chem., 91, 131-141, 2004.

Bond, T., Streets, D., Yarber, K., Nelson, S., Woo, J.-H., and Klimont, Z.: A technology-based global inventory of black and organic carbon emissions from combustion, J. Geophys. Res.Atmos., 109, doi:10.1029/2003JD003697, 2004.

Capaldo, K., Kasibhatla, P., and Pandis, S.: Is aerosol production within the marine boundary layer sufficient to maintain observed concentrations?, J. Geophys. Res. - Atmos., 104, 3483-3500, 1999.

Chin, M., Jacob, D., Gardner, G., Foreman-Fowler, M., Spiro, P., and Savoie, D.: A global three-dimensional model of tropospheric sulfate, J. Geophys. Res.-Atmos., 101, 18 667-18690, 1996.

Chin, M., Rood, R., Lin, S.-J., Müller, J.-F., and Thompson, A.: Atmospheric sulfur cycle simulated in the global model GOCART: Model description and global properties, J. Geophys. Res.-Atmos., 105, 24 671-24 687, 2000.

Chipperfield, M.: New Version of the TOMCAT/SLIMCAT offline chemical transport model: Intercomparison of stratospheric tracer experiments, Q. J. R. Meteorol. Soc., 132(617), 11791203, doi:10.1256/qj.05.51, 2006.

Chipperfield, M., Cariolle, D., Simon, P., Ramaroson, R., and Lary, D.: A three-dimensional modeling study of trace species in the Arctic lower stratosphere during winter 1989-90, J. Geophys. Res.-Atmos., 98, 7199-7218, 1993.

Clarke, A. and Kapustin, V.: A Pacific Aerosol Survey. Part I: A Decade of Data on Particle Production, Transport, Evolution, and Mixing in the Troposphere, J. Atmos. Sci., 59, 363-382, 2002.

Clarke, A., Davis, D., Kapustin, V., Eisele, F., Chen, G., Paluch, I., Lenschow, D., Bandy, A., Thornton, D., Moore, K., Mauldin, L., Tanner, D., Litchy, M., Carroll, M., Collins, J., and Albercook, G.: Particle Nucleation in the Tropical Boundary Layer and Its Coupling to Marine Sulfur Sources, Science, 282, 89-92, 1998.

Clarke, A., Owens, S., and Zhou, J.: An ultrafine sea-salt flux from breaking waves: Implications for cloud condensation nuclei in the remote marine atmosphere, J. Geophys. Res.-Atmos., 111, D06202, doi:10.1019/2005JD006565, 2006.

Covert, D., Kapustin, V., Quinn, P., and Bates, T.: New Particle Formation in the Marine Boundary Layer, J. Geophys. Res.-Atmos. 97, 20 581-20 589, 1992.

Covert, D., Kapustin, V., Bates, T., and Quinn, P.: Physical proper- 
ties of marine boundary layer aerosol particles of the mid-Pacific in relation to sources and meteorological transport, J. Geophys. Res.-Atmos., 101, 6919-6930, 1996.

Covert, D., Gras, J., Wiedensohler, A., and Stratmann, F.: Comparison of directly measured $\mathrm{CCN}$ with $\mathrm{CCN}$ modeled from the number-size distribution in the marine boundary layer during ACE 1 at Cape Grim, Tasmania, J. Geophys. Res.-Atmos., 103, 16 597-16 608, 1998.

Dentener, F., Kinne, S., Bond, T., Boucher, O. Cofala, J., Generoso, S., Ginoux, P., Gong, S., Hoelzemann, J., Ito, A., Marelli, L., Penner, J., Putaud, J.-P., Textor, C., Schulz, M., van der Werf, M., and Wilson, J.: Emissions of primary aerosol and precursor gases in the years 2000 and 1750 prescribed data-sets for AeroCom, Atmos. Chem. Phys., 6, 4321-4344, 2006,

http://www.atmos-chem-phys.net/6/4321/2006/.

Easter, R., Ghan, S., Zhang, Y., Saylor, R., Chapman, E., Laulainen, N., Abdul-Razzak, H., Leung, L., Bian, X., and Zaveri, R.: MIRAGE: Model description and evaluation of aerosols and trace gases, J. Geophys. Res.- Atmos., 109, D20210, doi:10.1029/2004JD004571, 2004.

Fitzgerald, J.: Marine aerosols: A review, Atmos. Environ., 25, 533-545, 1991.

Geever, M., O’Dowd, C., van Ekeren, S., Flanagan, R., Nilsson, E., and de Leeuw G, Rannik, U.: Submicron sea spray fluxes, Geophys. Res. Lett., 32, doi:10.1029/2005GL023 081, 2005.

Ghan, S., Easter, R., Hudson, J., and Breon, F.-M.: Evaluation of aerosol indirect radiative forcing in MIRAGE, J. Geophys. Res.Atmos., 106, 5317-5334, 2001.

Gong, S.: A parameterization of sea-salt aerosol source function for sub- and super-micron particles, Global Biogeochem. Cycles, 17, 1097-1103, 2003.

Gong, S., Barrie, L., and Lazare, M.: Canadian Aerosol Module (CAM): A size-segregated simulation of atmospheric aerosol processes for climate and air quality models, 2. Global seasalt and its budgets, J. Geophys. Res.-Atmos., 107, 4479, doi:10.1029/2001JD002004, 2002.

Gong, S., Barrie, L., Blanchet, J.-P., von Salzen, K., Lohmann, U., Lesins, G., Spacek, L., Zhang, L., Girard, E., Lin, H., Leaitch, R., Leighton, H., Chylek, P., and Huang, P.: Canadian Aerosol Module: A size-segregated simulation of atmospheric aerosol processes for climate and air quality models 1. Module development, J. Geophys. Res.-Atmos., 108, 4007, doi:10.1029/2001JD002002, 2003.

Heald, C., Jacob, D., Park, R., Russell, L. annd Huebert, B., Seinfeld, J., Liao, H., and Weber, R.: A large organic aerosol source in the free troposphere missing from current models, Geophys. Res. Lett., 32, doi:10.1029/2005GL023831, 2005.

Heintzenberg, J. and Bigg, E.: Tropospheric transport of trace substances in the southern hemisphere, Tellus, 42B, 355-363, 1990.

Heintzenberg, J., Covert, D., and Van Dingenen, R.: Size distribution and chemical composition of marine aerosols: a compilation and review, Tellus, Ser. B, 52B, 1104-1122, 2000.

Heintzenberg, J., Birmili, W., Wiedensohler, A., Nowak, A., and Tuch, T.: Structure, variability and persistence of the submicrometre marine aerosol, Tellus, Ser. B, 56B, 357-367, 2004.

Heintzenberg, J., Leck, C., Birmili, W., Wehner, B., Tjernström, M., and Wiedensohler, A.: Aerosol number-size distributions during clear and fog periods in the summer high Arctic, Tellus, 58B, 41-50, 2006.
Herzog, M., Weisenstein, D., and Penner, J.: A dynamic aerosol module for global chemical transport models: Model description, J. Geophys. Res.-Atmos., 109, D18202, doi:10.1029/2003JD004405, 2004.

Holtslag, A. and Boville, B.: Local versus nonlocal boundary layer diffusion in a globl climate model, J. Clim., 6, 1825-1842, 1993.

Huebert, B., Bates, T., Russell, P., Shi, G., KIm, Y., and Kawamura, K.: An overview of ACE Asia: Strategies for quantifying the relationships between Asian aerosols and their climatic impacts, J. Geophys. Res.-Atmos., 108(D23), 8633, doi:10.1029/2003JD003550, 2003.

Katoshevski, D., Nenes, A., and Seinfeld, J.: A study of processes that govern the maintenance of aerosols in the marine boundary layer, J. Aerosol Sci., 30, 503-532, 1999.

Kettle, A., Andreae, M., Amouroux, D., Andreae, T., Bates, T., Berresheim, H., Bingemer, H., Boniforti, R., Curran, M., DiTullio, G., Helas, G., Jones, G., Keller, M., Kiene, R., Leck, C., Levasseur, M., Malin, G., Maspero, M., Matrai, P., McTaggart, A., Mihalopoulos, N., Nguyen, B., Novo, A., Putaud, J., Rapsomanikis, S., Roberts, G., Schebeske, G., Sharma, S., Simö, R., Staubes, R., Turner, S., and Uher, G.: A global database of sea surface dimethylsulfide (DMS) measurements and a procedure to predict sea surface DMS as a function of latitude, longitude and month, Global Biogeochemical Cycles, 13, 399-444, 1999.

Koch, D., Jacob, D., Tegen, I., Rind, D., and Chin, M.: Tropospheric sulfur simulation and sulfate direct radiative forcing in the Goddard Institute for Space Studies general circulation model, J. Geophys. Res.-Atmos., 104, 23 799-23 822, 1999.

Kreidenweis, S., Penner, J., Yin, F., and Seinfeld, J.: The effects of dimethylsulfide upon marine aerosol concentrations, Atmospheric Environment Part A - General Topics, 25, 2501-2511, 1991.

Kulmala, M., Laaksonen, A., and Pirjola, L.: Parameterizations for sulfuric acid/water nucleation rates, J. Geophys. Res.-Atmos., 103, 8301-8307, 1998.

Kulmala, M., Vehkamäki, H., Petajda, T., Dal Maso, M., Lauri, A., Kerminen, V., Birmili, W., and McMurry, P.: Formation and growth rates of ultrafine atmospheric particles: a review of observations, J. Aerosol Sci., 35, 143-176, 2004.

Lauer, A. and Hendricks, J.: Simulating aerosol microphysics with the ECHAM4/MADE GCM - Part II: Results from a first multiannual simulation of the submicrometer aerosol, Atmos. Chem. Phys., 6, 5495-5513, 2006,

http://www.atmos-chem-phys.net/6/5495/2006/.

Lauer, A., Hendricks, J., Ackermann, I., Schell, B., Hass, H., and Metzger, S.: Simulating aerosol microphysics with the ECHAM/MADE GCM - Part I: Model description and comparison with observations, Atmos. Chem. Phys., 5, 3251-3276, 2005, http://www.atmos-chem-phys.net/5/3251/2005/.

Leck, C. and Bigg, E.: Aerosol production over remote marine areas - A new route, Geophys. Res. Lett., 23, 3577-3581, 1999.

Leck, C., Norman, M., Bigg, E., and Hillamo, R.: Chemical composition and sources of the high Arctic aerosol relevant for cloud formation, J. Geophys. Res.-Atmos., 107(D2), doi:10.1029/2001JD001463, 2002.

Leck, C., Tjernstrom, M., Matrai, P., Swietlicki, E., and Bigg, K.: Can marine micro-organisms influence melting of the Arctic pack ice?, EOS, 85, 25-36, 2004.

Lewis, E. and Schwartz, S.: Sea Salt Aerosol Production: Mech- 
anisms, Methods, Measurements, and Models - A Critical Review, American Geophysical Union, Washington, 2004.

Leck, C. and Bigg, E.: Source and evolution of the marine aerosol - A new perspective, Geophys. Res. Lett., 32, L19803, doi:10.1029/2005GL023651, 2005a.

Leck, C. and Bigg, E.: Biogenic particles in the surface microlayer and overlaying atmosphere in the central Arctic Ocean during summer, Tellus, 57B, 305-316, 2005b.

Lin, X., Chameides, W., Kiang, C., Stelson, A., and Berresheim, H.: A model study of the formation of cloud condensation nuclei in remote marine areas, J. Geophys. Res.-Atmos., 97, 18 161$18171,1992$.

Liss, P. and Merlivat, L.: The Role of Air-Sea Exchange in Geochemical Cycling, chap. Air-sea gas exchange rates: Introduction and synthesis, 113-127, D. Reidel, Norwell, Mass., 1986.

Lohmann, U. and Leck, C.: Importance of submicron surface-active organic aerosols for pristine Arctic clouds, Tellus, 57B, 261-268, 2005.

Martensson, E., Nilsson, E., Leeuw, G., Cohen, L., and Hansson, H.: Laboratory simulations and parameterization of the primary marine aerosol production, J. Geophys. Res.-Atmos., 108(D9), 4297, doi:10.1029/2002JD002263, 2003.

Meskhidze, N., Nenes, A., Conant, W., and Seinfeld, J.: Evaluation of a new cloud droplet activation parameterization with in situ data from CRYSTAL-FACE and CSTRIPE, J. Geophys. Res.Atmos., 110, D16202, doi:10.1029/2004JD005703, 2005.

Monahan, E., Spiel, D., and Davidson, K.: Oceanic Whitecaps, chap. A model of marine aerosol generation via whitecaps and wave disruption, 167-174, D. Reidel, Norwell, Mass., 1986.

Nenes, A. and Seinfeld, J.: Parameterisation of cloud droplet formation in global climate models, J. Geophys. Res.-Atmos., 108(D14), 4415, doi:10.1029/2002JD002911, 2003.

Nilsson, E., Rannik, U., Swietlicki, E., Leck, C., Aalto, P., Zhou, J., and Norman, M.: Turbulent aerosol fluxes aver the Arctic Ocean: 2. Wind-driven sources from the sea, J. Geophys. Res.-Atmos., 106, 32 139-32 154, 2001.

O'Dowd, C., Smith, M., Consterdine, I., and Lowe, J.: Marine aerosol, sea-salt, and the marine sulphur cycle: a short review, Atmos. Environ., 31, 73-80, 1997.

O'Dowd, C., McFiggans, G., Creasey, D., Pirjola, L., Hoell, C., Smith, M., Allan, B., Plane, J., Heard, D., Lee, J., Pilling, M., and Kulmala, M.: On the photochemical production of new particles in the coastal boundary layer, Geophys. Res. Lett., 26, 17071710, 1999.

O’Dowd, C., Facchini, M., Cavalli, F., Ceburnis, D., Mircea, M., Decesari, S., Fuzzi, S., Yoon, Y., and Putaud, J.: Biogenically driven organic contribution to marine aerosol, Nature, 431, 676680, 2004

Pandis, S., Russell, L., and Seinfeld, J.: The relationship between DMS flux and CCN concentration in remote marine regions, J. Geophys. Res.-Atmos., 99, 16 945-19 957, 1994.

Pawlowska, H. and Brenguier, J.: Microphysical properties of stratocumulus clouds during ACE 2, Tellus, 2000.

Pierce, J. and Adams, P.: Global evaluation of CCN formation by direct emission of sea salt and growth of ultrafine sea salt, J. Geophys. Res.-Atmos., 111, D06203, doi:10.1029/2005JD006186, 2006.

Pirjola, L., O'Dowd, C., Brooks, I., and Kulmala, M.: Can new particle formation occur in the clean marine boundary layer?, J.
Geophys. Res.-Atmos., 105, 26 531-26 546, 2000.

Prather, M.: Numerical Advection by Conservation of SecondOrder Moments, J. Geophys. Res.-Atmos., 91, 6671-6681, 1986.

Raes, F.: Entrainment of free tropsospheric aerosols as a regulating mechanism for cloud condensation nuclei in the remote marine boundary layer, J. Geophys. Res.-Atmos., 100, 2893-2903, 1995.

Raes, F. and Van Dingenen, R.: Simulations of condensation and cloud condenstaion nuclei from biogenic $\mathrm{SO}_{2}$ in the remote marine boundary-layer, J. Geophys. Res.-Atmos., 97, 12901$12912,1992$.

Raes, F., Wilson, J., and Van Dingenen, R.: Aerosol Forcing of Climate, chap. Aerosol Dynamics and its Implication for the global aerosol climatology, pp. 153-169, John Wiley and Sons, New York, 1995.

Raes, F., Van Dingenen, R., Cuevas, E., Van Vaethoven, P., and Prospero, J.: Observations of aerosols in the free troposphere and marine boundary layer of the subtropical notheast Atlantic: Discussion of processes determining their size distribution, J. Geophys. Res.-Atmos., 102, 21 315-21 328, 1997.

Raes, F., Bates, T., McGovern, F., and Vanliedekerke, M.: The second Aerosol Characterization Experiment (ACE 2): General overview and main results, Tellus, 52, 111-125, 2000.

Ramanathan, V., Crutzen, P., Kiehl, J., and Rosenfeld, D.: Aerosols, climate, and the hydrological cycle, Science, 294, 2119-2124, 2001.

Rasch, P., Barth, M., Kiehl, J., Schwartz, S., and Benkovitz, C.: A description of the global sulfur cycle and its controlling processes in the National Center for Atmospheric Research Community Climate Model, Version 3, J. Geophys. Res.-Atmos., 105, 1367-1385, 2000.

Rodriguez, M. A. and Dabdub, D.: IMAGES-SCAPE2: A modeling study of size- and chemically resolved aerosol thermodynamics in a global chemical transport model, J. Geophys. Res.Atmos., 109, D02203, doi:10/1029/2003JD003639, 2004.

Rossow, W. and Schiffer, R.: Advances in Understanding Clouds From ISCCP, Bulletin of the American Meteorological Society, 80, 2261-2287, 1999.

Russell, L., Pandis, S., and Seinfeld, J.: Aerosol production and growth in the marine boundary layer, J. Geophys. Res.-Atmos. 99, 20 989-21 003, 1994.

Russell, P. and Heintzenberg, J.: An overview of the ACE 2 Clear Sky Column Closure experiment (CLEARCOLUMN), Tellus, 52B, 463-483, 2000.

Spracklen, D., Pringle, K., Carslaw, K., Chipperfield, M., and Mann, G.: A global off-line model of size-resolved aerosol microphysics; I. Model development and prediction of aerosol properties, Atmos. Chem. Phys., 5, 2227-2252, 2005 a.

Spracklen, D., Pringle, K., Carslaw, K., Chipperfield, M., and Mann, G.: A global off-line model of size-resolved aerosol microphysics; II. Identification of key uncertainties, Atmos. Chem. Phys., 5, 3233-3250, 2005b.

Spracklen, D., Carslaw, K., Kulmala, M., Kerminen, V.-M., Mann, G., and Sihto, S.-L.: The contribution of boundary layer nucleation events to total particle concentrations on regional and global scales, Atmos. Chem. Phys., 6, 7323-7368, 2006, http://www.atmos-chem-phys.net/6/7323/2006/.

Stier, P., Feichter, J., Kinne, S., Kloster, S., Vignati, E., Wilson, J., Ganzeveld, L., Tegen, I., Werner, M., Balkanski, Y., Schulz, M., 
Boucher, O., Minikin, A., and Petzold, A.: The aerosol-climate ECHAM5-HAM, Atmos. Chem. Phys., 5, 1125-1156, 2005, http://www.atmos-chem-phys.net/5/1125/2005/.

Stockwell, D. and Chipperfield, M.: A tropospheric chemicaltransport model: Development and validation of the model transport schemes, Q. J. R. Meteorol. Soc., 125, 1747-1783, 1999.

Tang, Y., Carmichael, G., Kurata, G., Uno, I., Weber, R., Song, C.H., Guttikunda, S., Woo, J.-H., , Streets, D., Wei, C., Clarke, A., Huebert, B., and Anderson, T.: Impacts of dust on regional tropospheric chemistry during the ACE-Asia experiment: A model study with observations, J. Geophys. Res.- Atmos., 109, D19s21, doi:10.1029/2003JD003806, 2004.

Tiedtke, M.: A comprehensive mass flux scheme for cumulus parameterization in large scale models, Mon. Wea. Review, 117, 1779-1800, 1989.

Van der Werf, G., Randerson, J., Collatz, G., and Giglio, L.: Carbon emissions from fires in tropical and subtropical ecosystems, Global Change Biology, 9, 547-562, 2003.

Van Dingenen, R., Raes, F., and Jensen, N.: Evidence for anthropogenic impact on number concentration and sulfate content of cloud-processed aerosol particles over the North Atlantic, J. Geophys. Res.-Atmos., 100, 21 057-21 067, 1995.

Vehkamäki, H., Kulmala, M., Napari, I., Lehtinen, K., Timmreck, C., Noppel, M., and Laaksonen, A.: An improved parametrization for sulfuric acid-water nucleation rates for tropospheric and stratospheric conditions, J. Geophys. Res.-Atmos., 107, 46224631, 2002.
Verma, S., Boucher, O., Reddy, M., Upadhyaya, H., Le Van, P., Binkowski, F., and Sharma, O.: Modeling and analysis of aerosol processes in an interactive chemistry general circulation model, J. Geophys. Res.-Atmos., 112, D03207, doi:10.1029/2005JD006077, 2007.

Vignati, E., Wilson, J., and Stier, P.: M7: An efficient sizeresolved aerosol microphysics module for large-scale aerosol transport models, J. Geophys. Res.-Atmos., 109, D22202, doi:10.1029/2003JD004485, 2004.

Weber, R., McMurry, P., Eisele, F., and Tanner, D.: Measurement of expected nucleation precursor species and 3-500 nm diameter particles at Mauna Loa Observatory, Hawaii, J. Atmos. Sci., 52, 2242-2256, 1995.

Weber, R., McMurry, P., Mauldin, L., Tanner, D., Eisele, F., Brechtel, F., Kreidenweis, S., Kok, G., Schillawski, R., and Baumgardner, D.: A study of new particle formation and growth involving biogenic and trace gas species measured during ACE 1, J. Geophys. Res.-Atmos., 103, 16385-16396, 1998.

Wilson, J., Cuvelier, C., and Raes, F.: A modeling study of global mixed aerosol fields, J. Geophys. Res.-Atmos., 106, 34 08134 108, 2001.

Zhou, J., Swietlicki, E., Berg, O., Aalto, P., Hameri, K., Nilsson, E., and Leck, C.: Hygroscopic properties of aerosol particles over the central Arctic Ocean during summer, J. Geophys. Res.Atmos., 106, 32 111-32 123, 2001. 